\title{
Sudden Surface Warming-Drying Events Caused by Typhoon Passages across Taiwan*
}

\author{
TsING-CHANG CHEN AND SHIH-YU WANG \\ Department of Geological and Atmospheric Sciences, Iowa State University, Ames, Iowa \\ MING-CHENG YEN \\ Department of Atmospheric Science, National Central University, Chung-Li, Taiwan \\ AdAm J. Clark AND JENQ-DAR TSAY \\ Department of Geological and Atmospheric Sciences, Iowa State University, Ames, Iowa
}

(Manuscript received 30 June 2008, in final form 21 August 2009)

\begin{abstract}
Typhoon passages across Taiwan can generate sudden surface warming in downslope regions. Special characteristics and mechanisms for 54 such warming events that were identified during the 1961-2007 period are examined. Preferred warming regions were identified in northwest Taiwan, where warming is generated by downslope flow from east or northeast winds in westward-moving typhoons, and in southeast Taiwan, where it is generated by downslope flow from west or northwest winds in northwestward-moving typhoons. In addition to the orographic effect, warmings occurred exclusively within nonprecipitation zones of typhoons. Most northwest (southeast) warmings occur during the day (night) with an average lifetime of 4 (5) h, which roughly corresponds to the average time a nonprecipitation zone remains over a station. During the period examined, three typhoons generated warming events in both northwest and southeast Taiwan, and only Typhoon Haitang (2005) generated warmings with comparable magnitudes ( $\sim 12-\mathrm{K}$ increase) in both regions. For Typhoon Haitang as an example, diagnostic analyses with two different approaches reveal that the majority of the warming is contributed by downslope adiabatic warming, but the warming associated with the passage of a nonprecipitation zone is not negligible. Similar results were found when these two diagnostic approaches were applied to the other warming events. The diurnal mode of the atmospheric divergent circulation over East Asia-western North Pacific undergoes a clockwise rotation. The vorticity tendency generated by this diurnal divergent circulation through vortex stretching may modulate the arrival time of typhoons to cause daily (nighttime) warming in the northwest (southeast).
\end{abstract}

\section{Introduction}

Taiwan is a subtropical island (about $400 \mathrm{~km}$ long and $150 \mathrm{~km}$ wide) located in the western North Pacific Ocean. A north-south-oriented mountain range, with peaks approaching $4 \mathrm{~km}$ in elevation, divides the island into the western plains and a narrow eastern coastal zone. Because of this topographic feature, typhoons often have

\footnotetext{
* In memory of Professor Shyue-Yih Liao for his contribution to developing pioneering research of weather systems in East Asia.

Corresponding author address: Tsing-Chang (Mike) Chen, 3010 Agronomy Hall, Dept. of Geological and Atmospheric Sciences, Iowa State University, Ames, IA 50011.

E-mail: tmchen@iastate.edu
}

a profound interaction with the terrain of Taiwan and produce not only strong winds and heavy rainfall, but sometimes a sudden and intense warming and drying on the downwind side of the mountains (Liao 1979). Over the past two decades, a number of numerical studies (e.g., Bender et al. 1987; Lin et al. 1999; Yeh and Elsberry 1993; Wu 2001; Li et al. 2005) simulated various aspects of the typhoon-orography interaction over Taiwan. A terrain-induced low pressure formed by subsidence warming is a common feature produced by these simulations. The subsidence warming-drying events are not only a unique weather event to active typhoon regions but can also be disastrous to the agricultural industry in Taiwan. Rose and vegetable farms in the northwest and fruit farms in southeast Taiwan are often damaged by these warming-drying events, in addition 
TABLE 1. Basic characteristics of surface sudden warming events that occurred in northwest Taiwan during 23 typhoon passages: TY name, maximum warming temperature $T_{M}$, minimum relative humidity $\left(\mathrm{RH}_{m}\right)$, station name, and LST of peak warming; $T_{S}$ and $\mathrm{RH}$ are climatological $T_{S}$ and RH at the particular hour averaged over the analysis period of 1961-2005. The occurrence time of warming during 0600-1800 LST (1800-0600 LST) is considered as daytime (nighttime) and is indicated by regular (boldface) characters.

\begin{tabular}{|c|c|c|c|c|c|}
\hline TY name & Date & Station & $T_{M}\left(T_{S}\right)\left({ }^{\circ} \mathrm{C}\right)$ & $\mathrm{RH}_{m}(\mathrm{RH})(\%)$ & LST \\
\hline Elsie & 14 Jul 1961 & Taichung & $36.5(32)$ & $25.0(60)$ & 1200 \\
\hline Sally & 28 Sep 1961 & Taichung & $33.5(29)$ & $25.0(65)$ & 1600 \\
\hline Dinah & 3 Oct 1962 & Taichung & $36.0(29)$ & $32.0(64)$ & 1000 \\
\hline Faye & 5 Sep 1963 & Taichung & $36.5(31)$ & $30.0(64)$ & 1100 \\
\hline Sally & 9 Sep 1964 & Jiyuatan & $30.5(25)$ & $35.0(76)$ & 1100 \\
\hline Anita & 29 Jun 1967 & Jiyuatan & $29.0(26)$ & $45.0(75)$ & 1100 \\
\hline Wendy & 6 Sep 1968 & Taichung & $39.0(30)$ & $39.0(68)$ & 1000 \\
\hline Lucy & 21 Jul 1971 & Taichung & 34.0 (27) & $22.0(86)$ & 0000 \\
\hline Nora & 7 Oct 1973 & Taichung & $35.0(30)$ & $45.0(54)$ & 1400 \\
\hline Betty & 23 Sep 1975 & Taichung & 31.0 (24) & $40.0(87)$ & 0300 \\
\hline Hope & 1 Aug 1979 & Taichung & 35.0 (27) & $15.0(85)$ & 2200 \\
\hline Wayne & 25 Jul 1983 & Taichung & $35.5(32)$ & $27.0(61)$ & 1400 \\
\hline Wynne & 24 Jun 1984 & Jiyuatan & $30.5(23)$ & $40.0(84)$ & 0800 \\
\hline Gerald & 10 Sep 1987 & Jiyuatan & $27.0(23)$ & $40.0(91)$ & 0700 \\
\hline Amy & 19 Jul 1991 & Taichung & $34.0(27)$ & $25.0(84)$ & 0700 \\
\hline Nat & 23 Sep 1991 & Taichung & $35.0(30)$ & $15.0(63)$ & 1200 \\
\hline Gloria & 26 Jul 1996 & Taichung & $37.0(31)$ & $14.0(66)$ & 1600 \\
\hline Sally & 8 Sep 1996 & Jiyuatan & $30.5(26)$ & $31.0(74)$ & 1400 \\
\hline Kaita & 7 Jul 2000 & Jiyuatan & $32.5(26)$ & $19.0(78)$ & 1100 \\
\hline Chebi & 22 Jun 2001 & Jiyuatan & $28.5(23)$ & $35.0(90)$ & 1700 \\
\hline Mindulle & 1 Jul 2004 & Taichung & $39.7(31)$ & $36.0(64)$ & 1500 \\
\hline Haitang & 18 Jul 2005 & Chunghua & 38.0 (26) & $37.5(88)$ & 0100 \\
\hline Longwang & 2 Oct 2005 & Taichung & 36.0 (24) & $40.2(87)$ & 0200 \\
\hline
\end{tabular}

to damage caused by high winds and heavy rainfall (S.-H. Chen et al. 2007).

Liao (1979) compiled nine surface warming events caused by typhoon passages across or near Taiwan during the period of 1949-68: five warmings in northwestern Taiwan and four in southeast Taiwan. The first group was generated by typhoons propagating across southern Taiwan or the ocean south of this island, whereas the second group was induced by typhoons moving across or to the northeast of northern Taiwan. Climatologically, three or four typhoons cross Taiwan each year (Chang and Chien 2005) and on average at least one produces sudden surface warming (as shown in Tables 1 and 2). Despite previous studies that simulated the typhooninduced downslope warming in southeast Taiwan, there has not been a systematic analysis of the warming characteristics since Liao's (1979) pioneer study. A number of salient features of these warming events have not been well documented: 1) geographic preference and associated typhoon trajectories, 2) lifetime and timing of warming events, 3) double warmings (occurring simultaneously on two sides of Taiwan), and 4) warming mechanisms in addition to adiabatic warming from downslope flow. In the past three decades, modern meteorological observational methods have been developed in Taiwan, making it possible to analyze and document these features in a climatological perspective.
During the passage of Typhoon (TY) Haitang over Taiwan on 18 July 2005, two unusually intense warming/ drying events occurred in the northwest and southeast regions of Taiwan. In both regions within a couple of hours, temperatures rose from around $26^{\circ}-28^{\circ} \mathrm{C}$ to $38^{\circ} \mathrm{C}$, while the relative humidity decreased from $80 \%$ to $30 \%$. These events resulted in an unprecedented agricultural disaster with hundreds of millions of dollars in damages incurred because of the sudden desert-like heat and dryness (China Times, 20 July 2005, and the Taiwan government report, available online at http://www.dgbas. gov.tw/public/Data/88111254171.pdf). This typhoon was one of three documented during the time period examined that generated warmings on both sides of Taiwan and was the only typhoon that generated these warmings with comparable magnitude. It is the intent of this study to document some of these features with unique radar imagery and temperature-relative humidity time series from when the warming-drying events occurred associated with TY Haitang. In addition, to put the warming-drying events associated with this typhoon into a climatological context, past warming events in Taiwan are documented and another thermal process is suggested, in addition to adiabatic warming caused by downslope flow, which may have contributed to the warming-drying events.

This paper is outlined as follows: The observational data used are described in section 2. Unique features 
TABLE 2. As in Table 1, but for 31 surface sudden warming events that occurred in southeast Taiwan.

\begin{tabular}{|c|c|c|c|c|c|}
\hline TY name & Date & Station & $T_{M}\left(T_{S}\right)\left({ }^{\circ} \mathrm{C}\right)$ & $\mathrm{RH}_{m}(\mathrm{RH})(\%)$ & LST \\
\hline Pamela & 12 Sep 1961 & Taitung & $33.5(26)$ & $49.0(84)$ & 0300 \\
\hline Opal & 6 Aug 1962 & Taitung & 32.2 (27) & $50.0(83)$ & 0000 \\
\hline Amy & 5 Sep 1962 & Taitung & $33.5(30)$ & $48.0(72)$ & 1200 \\
\hline Wendy & 6 Jul 1963 & Taitung & $33.5(30)$ & $50.0(71)$ & 1000 \\
\hline Gloria & 11 Sep 1963 & Taitung & $35.1(26)$ & $25.0(84)$ & 0200 \\
\hline Mary & 19 Aug 1965 & Taitung & 33.4 (27) & $30.0(83)$ & 0100 \\
\hline Elsie & 26 Sep 1969 & Taitung & 35.0 (25) & $28.0(82)$ & 2300 \\
\hline Bess & 23 Sep 1971 & Hsinkang & 37.0 (27) & 15.0 (79) & 0000 \\
\hline Betty & 16 Aug 1972 & Hsinkang & 36.0 (27) & $27.0(84)$ & 2300 \\
\hline Billie & 9 Aug 1976 & Hsinkang & 37.0 (29) & $10.0(82)$ & 2200 \\
\hline Norris & 27 Aug 1980 & Taitung & 33.0 (27) & $47.0(83)$ & 2300 \\
\hline Cecil & 10 Aug 1982 & Taitung & 34.0 (27) & $19.0(81)$ & 0000 \\
\hline Freda & 7 Aug 1984 & Taitung & $34.5(31)$ & $38.0(72)$ & 1500 \\
\hline Nelson & 23 Aug 1985 & Taitung & $35.2(30)$ & $30.0(69)$ & 0900 \\
\hline Brenda & 4 Oct 1985 & Taitung & $37.5(28)$ & $5.0(66)$ & 0900 \\
\hline Sarah & 12 Sep 1989 & Taitung & $35.7(26)$ & 31.0 (82) & 0000 \\
\hline Yancy & 19 Aug 1990 & Taitung & $38.5(31)$ & $13.0(70)$ & 1200 \\
\hline Doug & 8 Aug 1994 & Hsinkang & $38.0(26)$ & 31.0 (84) & 0200 \\
\hline Seth & 10 Oct 1994 & Taitung & 38.2 (24) & 28.0 (78) & 0200 \\
\hline Herb & 31 Jul 1996 & Hsinkang & 35.0 (29) & 41.0 (79) & 2200 \\
\hline Winnie & 18 Aug 1997 & Taitung & $37.1(26)$ & 35.0 (81) & 0400 \\
\hline Zeb & 16 Oct 1998 & Dawu & $34.5(26)$ & $41.0(73)$ & 0800 \\
\hline Nari & 17 Sep 2001 & Dawu & 32.1 (25) & $47.0(83)$ & 0200 \\
\hline Sinlaku & 7 Sep 2002 & Dawu & $36.0(30)$ & $28.0(72)$ & 1100 \\
\hline Mindulle & 3 Jul 2004 & Hsinkang & 32.8 (29) & 44.0 (78) & 0300 \\
\hline Aere & 24 Aug 2004 & Taitung & $36.8(30)$ & $39.0(76)$ & 1600 \\
\hline Haitang & 18 Jul 2005 & Hsinkang & $38.1(26)$ & 34.0 (83) & 0600 \\
\hline Matsa & 4 Aug 2005 & Taitung & 36.5 (27) & 30.0 (85) & 0100 \\
\hline Talim & 31 Aug 2005 & Hsinkang & 36.2 (29) & 43.0 (78) & 0000 \\
\hline Longwang & 2 Oct 2005 & Taitung & $32.9(24)$ & $39.0(83)$ & 0200 \\
\hline Krosa & 7 Oct 2007 & Hsinkang & $38.5(31)$ & $37.0(72)$ & 1500 \\
\hline
\end{tabular}

found from a systematic analysis of 54 warming events that were identified during 1961-2007 are reported in section 3. Some pronounced warming features of TY Haitang are presented in section 4 and, based on these features, an analysis was conducted to explore the possible effects of the typhoon rainbelt structure on these warming events. This analysis was extended to cover all other warming events examined and findings from this analysis are shown in section 5 . A potential mechanism for the day-night difference of the preferred occurrence times between the northwest and southeast warming events is explored in section 6 . The summary and concluding remarks are provided in section 7 .

\section{Data and radar composite methods}

A dense surface observational network was developed collaboratively by several government agencies in Taiwan (Fig. 1), which includes an Automatic Rainfall and Meteorological Telemetry System (ARMTS) of more than 300 rain gauges (Chen et al. 1999), 23 conventional stations managed by the weather bureau of Taiwan, 72 stations monitored by the Environmental Protection Administration, and military-based surface observing sites. All the stations have provided hourly observations since 1993, although the 23 weather bureau stations have provided three-hourly observations since 1961 . The climatological analyses of sudden surface warming events generated by the typhoon-orography interaction were made with only observations from the weather bureau stations during the past $47 \mathrm{yr}$. Upper-air sounding stations at Taipei [World Meteorological Organization (WMO) 46692] and Hualian (WMO 46699) are denoted by balloon symbols in Fig. 1. The 6-h best track records of typhoons issued by the Japan Meteorological Agency (JMA) for the period of 19612007 were also used.

A network of four Doppler radars, which consists of a Weather Surveillance Radar-1988 Doppler (WSR-88D) radar at Wu-Fan-Shan (WF) and three SELEXGematronik, GmbH, METEOR 1500S Doppler radars at Chiku (CG), Kenting (KT), and Hualien (HL), covers Taiwan (Fig. 1). Images of composite radar reflectivities are operationally issued by the weather bureau of Taiwan. Raw radar reflectivity data corresponding to typhoon 


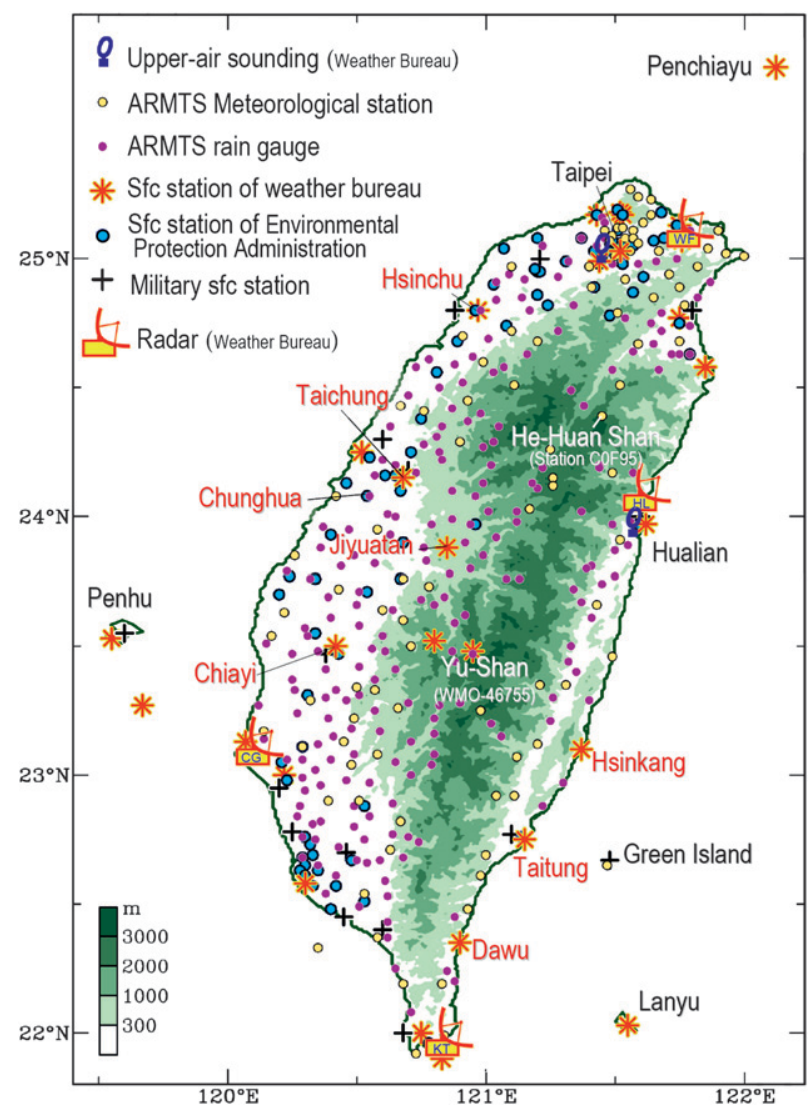

FIG. 1. Facilities of meteorological observations administrated by different government agencies (as listed in upper-left) in Taiwan.

passages across Taiwan during the period 2001-07 were processed through the following procedures: 1) interpolate the original data onto a Cartesian grid with a grid spacing of $1 \mathrm{~km}$ using the sorted position radar interpolation (SPRINT; Mohr et al. 1986; Miller and Fredrick 1999) software provided by the National Center for Atmospheric Research (NCAR), 2) merge the interpolated reflectivities from multiple radars using the NCAR Custom Editing and Display of Reduced Information in Cartesian space (CEDRIC) software (Mohr et al. 1986; Miller and Fredrick 1998), and 3) composite the highest reflectivity value measured in a vertical column for all elevation angles collected during the volume scan.

The day-night difference in the preferred occurrence times of warming events on both sides of Taiwan (examined in section 6) is explored using data generated by two sources. The first one is the reanalysis dataset produced by the Goddard Earth Observing System, version 5, (GEOS-5) data assimilation system under the Modern Era Retrospective-Analysis for Research and Applications (MERRA) project (Rienecker et al. 2008), which has a temporal resolution of $3 \mathrm{~h}$ and a horizontal reso- lution of $1.25^{\circ}$ longitude $\times 1.0^{\circ}$ latitude with 42 vertical levels and covers the period 1979-2005. The other one is the composite first-day forecast produced by the National Centers for Environmental Prediction (NCEP) Global Forecast System (GFS; Kanamitsu et al. 1991; Yang et al. 2006) for the period 2006-08. The GFS forecast has a temporal resolution of $3 \mathrm{~h}$ and a horizontal resolution of $1^{\circ}$ longitude $\times 1^{\circ}$ latitude with 18 vertical levels. Diurnal modes of the large-scale circulation depicted by these two data sources over the analysis domain have a close resemblance. Although these datasets were created for different purposes, they were used to cover the period 1979-2008 in our analysis.

\section{Characteristics of sudden surface-warming events associated with typhoon passages}

As shown in Fig. 2a, four surface stations are within each preferred warming region. Standard deviations (SDs) of hourly temperature and relative humidity at these eight stations were calculated for all 47 typhoon seasons (June-September). Hourly SDs at each individual station are averaged to compute a daily-mean SD. Eventually, an eight-station averaged daily-mean SD is generated by summing up the daily-mean SDs of eight stations. The eight-station average SDs of temperature and relative humidity are $3.6 \mathrm{~K}$ and $12 \%$, respectively. Warmings events are declared when $\Delta T_{M}\left(=T_{M}-\bar{T}_{S}\right) \geq$ $3.5 \mathrm{~K}$ and $\Delta \mathrm{RH}_{m}\left(=\overline{\mathrm{RH}}-\mathrm{RH}_{m}\right) \geq 12 \%$. Here, $T_{M}$ and $\mathrm{RH}_{m}$ are the maximum hourly temperature and minimum relative humidity, respectively, during the surface warming, whereas $\bar{T}_{S}$ and $\overline{\mathrm{RH}}$ are the corresponding climatological hourly temperature and relative humidity at the same time as $T_{M}$ and $\mathrm{RH}_{m}$ are measured. A typhoon passage across Taiwan is identified when the radius of $15 \mathrm{~m} \mathrm{~s}^{-1}(\simeq 30 \mathrm{kt})$ or when above winds cover Taiwan during the warming. All warming events were verified against the JMA typhoon-track records. Consistent with Liao's (1979) observations, warming events were concentrated in northwest and southeast Taiwan. The identified cases are tabulated with typhoon name, date, $T_{M}, \bar{T}_{S}, \mathrm{RH}_{m}, \overline{\mathrm{RH}}$, and timing of $T_{M}$ and $\mathrm{RH}_{m}$ in Table 1 for the northwest group (23 cases) and Table 2 for the southeast group (31 cases). Several systematic preferences of these warming events were observed.

\section{a. Geographic preference and related typhoon trajectories}

The warming occurrences over the past 47 typhoon seasons (June-October) are shown in Fig. 2a. The preferred regions appear in northwest Taiwan between Hsinchu (northwest) and Chiayi (central west) and for southeast 


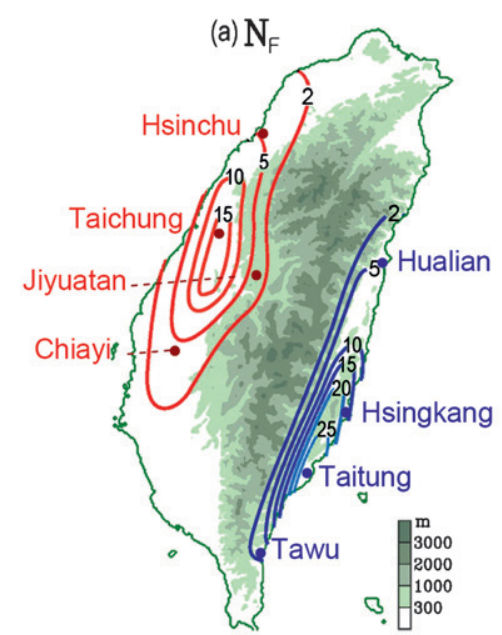

FIG. 2. Preferred regions of surface sudden warmings, trajectories (red/blue lines) of typhoons related to warmings, and locations of typhoon centers (red/blue dots) when warming occurred during the 1961-2007 typhoon seasons: (a) occurrence frequency $\left(N_{F}\right)$ detected by surface stations over the preferred warming regions, (b) trajectories and location of typhoon centers related warmings in northwest Taiwan, and (c) as in (b), but for southeast Taiwan.

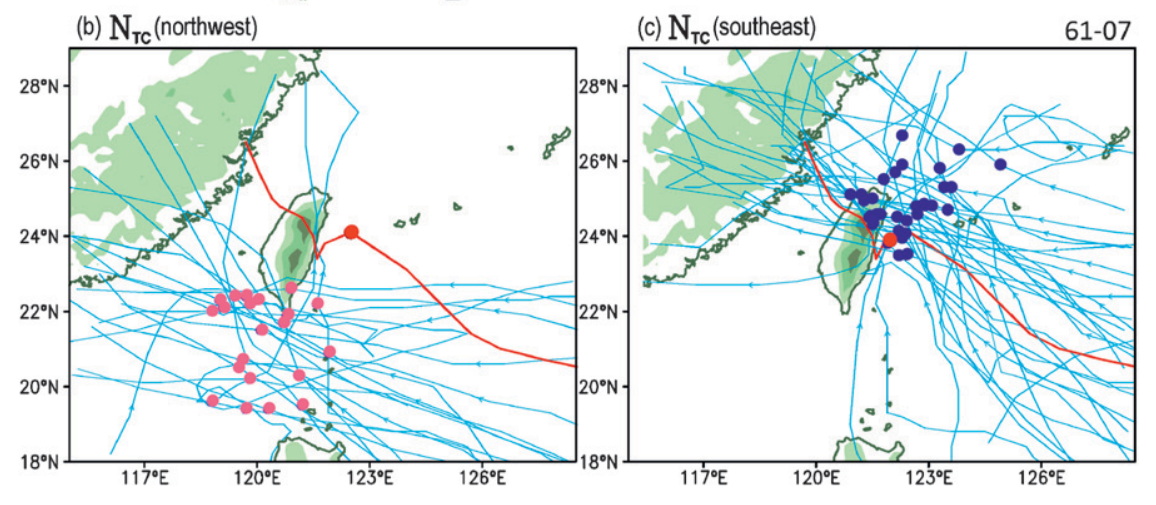

Taiwan between Hualian (central east) and Tawu (southeast). The northwest warming group is linked to westwardpropagating typhoons across the southern tip of Taiwan or the ocean south of Taiwan (Fig. 2b), whereas the southeast warming group is mainly caused by typhoons propagating northwestward across northern Taiwan and the ocean off the northeast coast (Fig. 2c). Thus, warmings in the first (second) region are likely caused by northeasterly or easterly (northwesterly or westerly) typhoon flows. The preferred wind directions are related to the preferred trajectories of typhoons and positions of these typhoons' centers (red/blue dots) when warmings occur.

Most typhoons that crossed the northern and southern parts of Taiwan generated a surface warming only on one side of the mountain range. On the other hand, TY Haitang crossing central Taiwan generated warming events with comparable magnitude on both the east and west sides of the mountain range. This double warming event will be examined later. Most of the typhoon trajectories linked to the northwest warming group are located south of Haitang (Fig. 2b), and those associated with the southeast warming group are mostly located north of Haitang (Fig. 2c). The trajectory of TY Haitang appears to separate these two groups of typhoons.

\section{b. Timing and lifetime of warming}

Shown in Figs. 3a,b are the local standard time (LST) of warming occurrences in the two preferred regions, in terms of a 24-h clock with maximum $\Delta T_{M} \mathrm{~s}$ as radii. The clock is divided into day (0600-1800 LST) and night (1800-0600 LST). It is found that most of the northwest warming cases (18 out of 23 ) occurred during day, whereas the majority of the southeast warming cases (21 out of 30) took place during night (particularly midnight-early morning). Based on Figs. 2b,c, most of the former (latter) cases occurred when the typhoon centers are located over the ocean south (northeast) of Taiwan. The arrival times of these two groups of typhoons are not determined by the typhoon-orography interaction but by the large-scale environmental flow in which these typhoons are embedded (discussed in section 6).

Let us define $\Delta T_{S} \equiv T_{S}-\bar{T}_{S}$ ( $T_{S}$ is surface temperature at a given hour and $\bar{T}_{S}$ the climatological temperature at that hour) and $\Delta \mathrm{RH} \equiv \overline{\mathrm{RH}}-\mathrm{RH}$ (relative humidity change corresponding to the same definition as $\Delta T_{S}$ ) over the potential warming areas. As long as $\Delta T_{M} \geq 3.5 \mathrm{~K}$ and $\mathrm{RH}_{m} \leq 55 \%$, the life span of warming events is considered to be the time period during which Taiwan is covered 

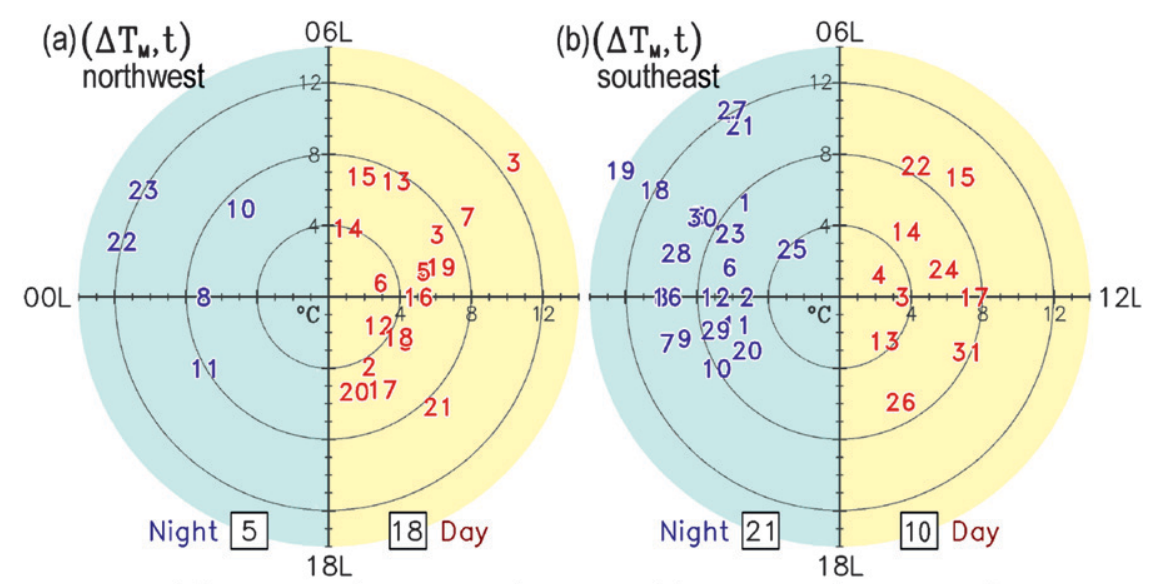

(c)Duration(northwest)

(d)Duration(southeast)
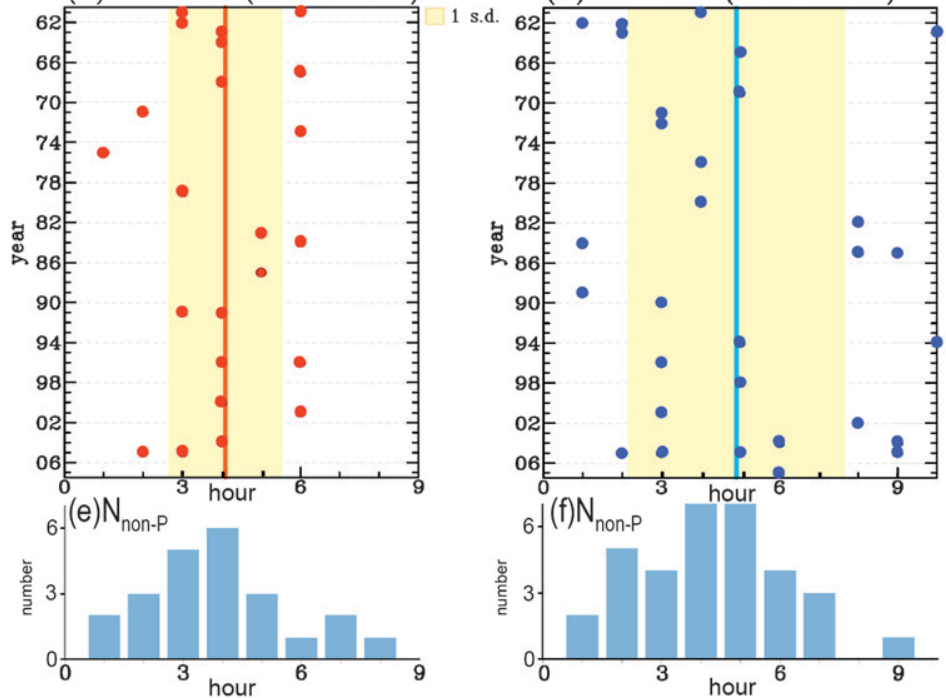

FIG. 3. The timing preference of warmings in terms of a 24-h clock for (a) warmings in northwest Taiwan and (b) warmings in southeast Taiwan, with the magnitude of $\Delta T_{M}$ measured by the radius. Nighttime (1800-0600 LST) and daytime (0600-1800 LST) are shaded in light blue and light yellow, respectively. Event numbers correspond to those in Tables 1 and 2 for each group. Life spans of warming events in the (c) northwest (red dots) and (d) southeast (blue dots) groups. The averaged duration of all events in each group is indicated by the color of the vertical line. Populations of nonprecipitation bands with different time spans across the warming station at (e) northwest and (f) southeast Taiwan.

by the $15 \mathrm{~m} \mathrm{~s}^{-1}(\simeq 30 \mathrm{kt})$ wind radius of a typhoon, and $\Delta T_{S} \geq$ one $\mathrm{SD}$ of $T_{S}$ and $\Delta \mathrm{RH} \geq$ (one SD of $\mathrm{RH}$ ) over the potential warming areas. Results are shown in Figs. 3c,d for the northwest and southeast groups, respectively. The average warming duration is about $4 \mathrm{~h}$ for the northwest group and $5 \mathrm{~h}$ for the southeast group.

\section{c. Surface temperature change from rainbelt to nonprecipitation zone}

The precipitation associated with typhoons occurs in spiral rainbands that have nonprecipitation zones between them. Radar reflectivities associated with typhoons producing warming events since 2001 (Fig. 4a) reveal that warming events only occur within these nonprecipitation zones. The duration that station rainfall remains below $0.5 \mathrm{~mm} \mathrm{~h}^{-1}$ (i.e., the minimum rainfall amount recordable by the rain gauge network in Taiwan) is defined as the duration of the nonprecipitation zone. The frequency of nonprecipitation zones across the warming stations with different time periods (Figs. $3 e$ and $\mathrm{f}$ ) reveals that the time of passage of these nonprecipitation zones coincides with the life span of warming events in both the northwest and southeast regions.

It was observed that the surface temperature $\left(T_{S}\right)$ during afternoon/evening thunderstorms in the Taipei 
(a)

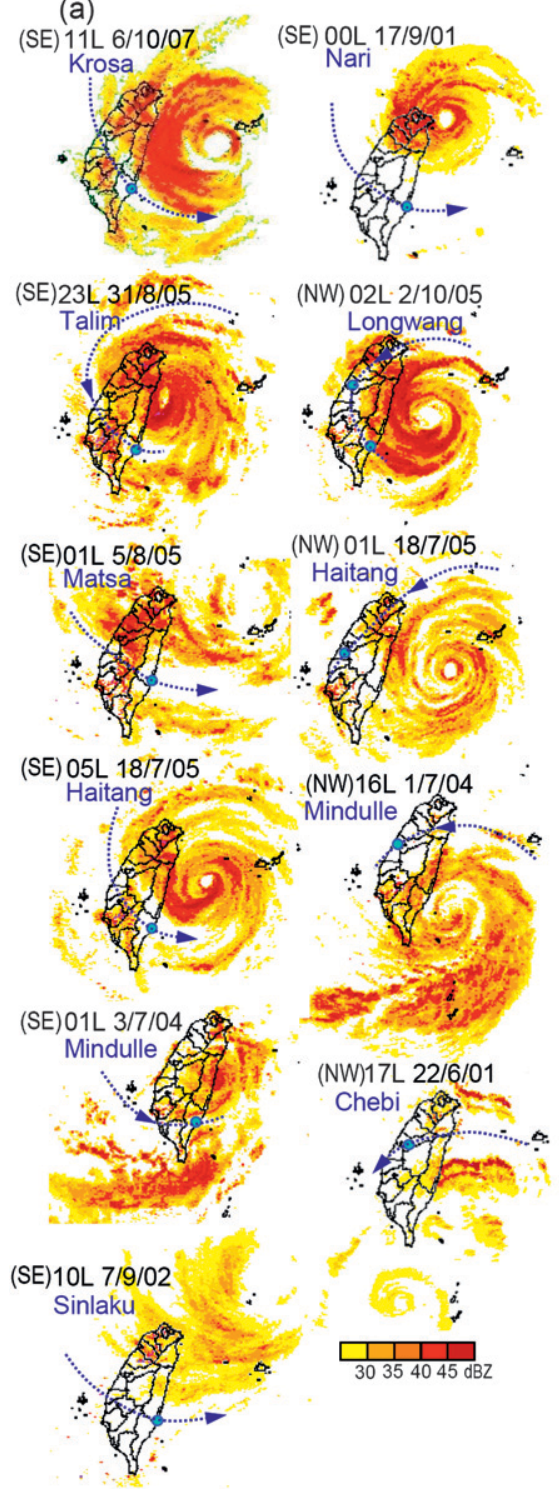

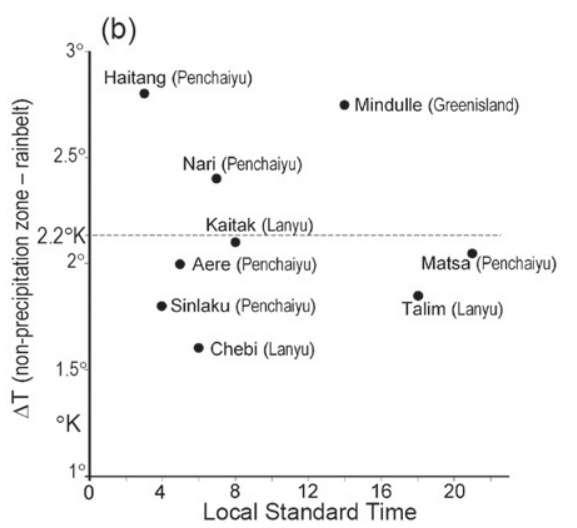

FIG. 4. (a) Composite radar reflectivity during warming events associated with typhoon passages, shown by two groups: southeast (SE) and northwest (NW). Stations in which maximum warming occurred are marked by light blue dots. Nonprecipitation zones associated with each typhoon are indicated by blue-dotted arrow lines. The time (day/ month/year) of events and the name of associated typhoons are given at the upper-left of each plot. Scale of reflectivity $(\mathrm{dB} Z)$ is given at the bottom-right of (a). (b) Maximum temperature difference between the passage of typhoon rainbelt and nonprecipitation zone vs the occurrence at local standard time of this maximum temperature difference (dots) measured at islands surrounding Taiwan. The name of each typhoon is given next to each dot followed by the island name.
Valley drops about $4-5 \mathrm{~K}$ but rises $2-3 \mathrm{~K}$ when the thunderstorm is over (T.-C. Chen et al. 2007). Powell (1990a,b) observed that the subsidence outside typhoon rainbelts is caused by compensating downward motion. A $T_{S}$ increase, thus, seems likely from a typhoon rainbelt to a nonprecipitation zone. This conjecture is substantiated in terms of the maximum $T_{S}$ change $\left(\Delta T_{S}\right)$ measured by surface stations at small islands around Taiwan. The purpose of using the observations of these island stations is to avoid any possible adiabatic warming caused by orographic downslope flow. These maximum $\Delta T_{S}$ for all typhoons presented in Fig. 4a are shown in Fig. 4b; the variation of $\Delta T_{S}$ covers a range of $1.5-3 \mathrm{~K}$, with an average of $2.2 \mathrm{~K}$. Positive $\Delta T_{S}$ for all typhoons in Fig. $4 \mathrm{a}$ suggest that the temperature increase from rainbelt to nonprecipitation zone contributes to the downslope warming.

\section{d. Double warmings}

In the past 47 typhoon seasons (1961-2007), only three typhoon passages across Taiwan generated warmings on both sides of Taiwan: Mindulle (3 July 2004), Longwang (2 October 2005), and Haitang (18 July 2005). It is of interest to note that the occurrence of these three double warming events was unusually clustered in 2004-05, which underwent minor warming (cooling) over the National Oceanic and Atmospheric Administration (NOAA) Niño-3.4 (western tropical Pacific) region. The occurrences of the three double warmings during these two typhoon seasons may be just a coincidence. 
The trajectories of Longwang and Haitang were similar in such a way that both made landfall at Hualian in east Taiwan and generated warmings a few hours before making landfall. The warmings of Haitang on both sides of Taiwan were comparable $\left(\sim 38^{\circ} \mathrm{C}\right)$, whereas those of Longwang were asymmetric. The southeast warming of Longwang was considerably milder $\left(\sim 33^{\circ} \mathrm{C}\right)$ relative to its northwest warming. As revealed from the radar image shown in Fig. 4a, the latter warming occurred in the downwind of a narrow nonprecipitation zone; however, the former warming took place along a nonprecipitation zone with an ill-organized outer rainbelt. Intensity of downslope flow (not shown) and warmings over these two warming regions seem to be reflected by the contrast between the rainbelt and nonprecipitation zone structure.

Changing its direction northward near the Luzon Island on 29 June 2004, Mindulle moved along a southnorth-oriented track off the east coast of Taiwan and did not make landfall. This track allowed Mindulle to cross typhoon tracks of both warming groups (Figs. 2b,c). The Mindulle-induced double warming events are also asymmetric, with the maximum temperature close to $40^{\circ} \mathrm{C}$ at Taichung (northwest) and $32^{\circ} \mathrm{C}$ at Hsinkang (southwest). The northwest warming happened when the center of Mindulle was located over the ocean close to the southeast coast of Taiwan (Fig. 4a). In contrast, the southeast warming occurred when this typhoon center was outside the range $(\sim 260 \mathrm{~km})$ of the Taiwan radar network. The difference in the distance of the typhoon from the warming location suggests that the asymmetric warmings are likely a result of the asymmetric intensity of downslope flows.

\section{Radar reflectivities of TY Haitang}

As previously mentioned, the passage of Haitang across Taiwan induced comparable sudden surface warmings in both northwest and southeast Taiwan. This typhoon will be used to illustrate some characteristics and to explore the possible cause of sudden surface warming. According to the JMA typhoon track records, Haitang formed on 11 July 2005 as a tropical depression in the central western Pacific and developed later into a supertyphoon before making landfall in Taiwan at 1450 LST 18 July. When the eye of Haitang was about $150 \mathrm{~km}$ from the east coast of Taiwan at 0100 LST (18 July $2005)$, heavy rainfall occurred in northern Taiwan, as indicated by the large values $(\geq 40 \mathrm{dBZ})$ of radar reflectivity (Rf) over this region (Fig. 5a). This heavy rainfall seemed to be caused by orographic lifting, as northeasterly winds associated with the outer circulation of Haitang encountered the northern mountain range in Taiwan. Located on the lee side of the northern moun- tains, the Chunghua station administered by the Environmental Protection Administration (indicated by a red dot in Fig. 5a) was embedded within a nonprecipitation zone in northwest Taiwan. The time series of surface temperature $\left(T_{S}\right)$ and relative humidity $(\mathrm{RH})$ at this station (Fig. 5b) indicate that the $T_{S}$ increased to $38^{\circ} \mathrm{C}$ while the RH dropped to $37.5 \%$ at 0100 LST. The dewpoint $\left(T_{d}\right)$ is a good indicator of the water vapor content of the air (Wallace and Hobbs 2006). As inferred from the $T_{d}$ decrease (3-4 K), the RH decrease is partially caused by the warming, but the drying is a result of the $T_{d}$ decrease. The duration of the entire warmingdrying event was approximately $4 \mathrm{~h}$.

Approximately $4 \mathrm{~h}$ after the peak warming-drying occurred at Chunghua, the eye of Haitang had moved to less than $100 \mathrm{~km}$ from the east coast of Taiwan. The rainfall in northern Taiwan had intensified since 0100 LST (Fig. 5c) and appeared to be associated with the principal rainband of Haitang. Meanwhile, lighter rainfall was occurring over the southwestern slopes of the southern mountain range, and a clear nonprecipitation zone was observed in southeast Taiwan extending from the downwind side of the southern mountains into the ocean. An observing station, Hsingkang (WMO 46761), in southeast Taiwan was located within this nonprecipitation zone. The time series of $T_{S}$ and $\mathrm{RH}$ at this station (Fig. 5d) indicates that $T_{S}$ increased from $26^{\circ} \mathrm{C}$ to $38.1^{\circ} \mathrm{C}$ while $\mathrm{RH}$ dropped from $90 \%$ to $34 \%$ within a 2-h period beginning at $0400 \mathrm{LST}$ and ending at $0600 \mathrm{LST}$. At the same time, $T_{d}$ fell from $24^{\circ} \mathrm{C}$ to $19^{\circ} \mathrm{C}$. Similar to the warming-drying event in northwest Taiwan, the event in southeast Taiwan lasted around $4 \mathrm{~h}$ within a nonprecipitation zone.

\section{Mechanisms for sudden surface warming-drying}

To infer possible mechanisms generating the sudden surface-warming-drying events associated with Haitang, rainfall histograms and time series of wind vectors for surface stations along the western plains and east coast of Taiwan (Fig. 6a) are arranged in Figs. 6b,c, respectively. The times and stations at which the warming-drying events occurred are highlighted in yellow. The strong easterly winds in the western plains and the strong westerly winds in the east coast at the time of the warmingdrying suggest that adiabatic warming from downslope flows was likely a primary cause of the warming-drying. Note that both warming/drying events occurred outside or between the typhoon rainbelts, which corresponds to the nonprecipitation zones indicated by the radar imagery in Fig. 5. This coincidence between the warmingdrying and the nonprecipitation zone suggests that an additional mechanism exists in the nonprecipitation zone 

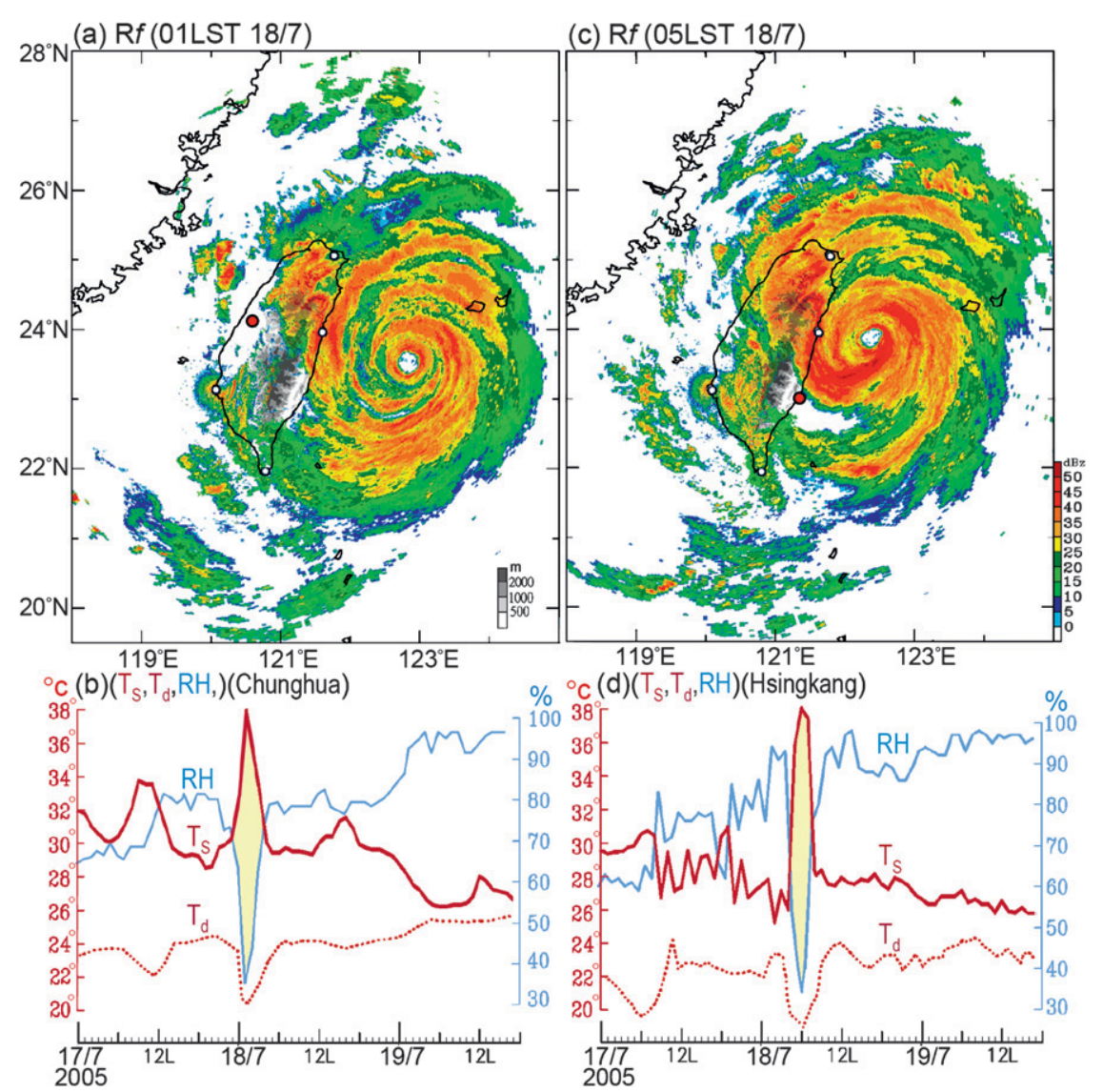

FIG. 5. Reflectivities of TY Haitang at (a) 0100 LST and (c) 0500 LST on 18 Jul 2005 and time series of $T_{S}$ (red solid), $T_{d}$ (red dotted), and RH (blue solid) at (b) Chunghua, $\left(T_{S}, T_{d}\right.$, and RH; Chunghua) and at (d) Hsingkang $\left(T_{S}, T_{d}\right.$, and RH; Hsingkang). Station Chunghua (EP 033) and Hsingkang (WMO 46761) are marked by a red dot in the central west and southeast of Taiwan, respectively. Four radar stations are marked by small circles. The surface sudden warmingdryness spells at both stations are shaded light yellow.

to facilitate the occurrence of the surface warming. These suggestions may be substantiated by two different diagnostic approaches: 1) downslope adiabatic warming and 2) thermal tendency caused by air mass redistribution. The crosschecking of results obtained by two different approaches strengthens the suggested mechanism of sudden surface warming.

\section{a. Downslope adiabatic warming}

Using the global operational forecasts of the European Centre for Medium-Range Weather Forecasts and results obtained from the Mesoscale Alpine Program, Drechsel and Mayr (2008) claimed that the foehn occurrence can be forecasted by the probability density function of cross-barrier pressure differences and the descent of isentropes. Drechsel and Mayr's approach is derived from the adiabatic warming of a descending air parcel, which can be estimated by the vertical advection of potential temperature from a given altitude to the surface. Because upper-air soundings are only available twice daily, it is impossible to obtain a good depiction of the temporal evolution of any surface warming event during the passage of typhoons using these soundings. However, surface observations are provided hourly, thus, it is possible to estimate the adiabatic warming generated by downslope flow using these observations. At the warming location, the local tendency in potential temperature can be expressed as

$$
\frac{\partial \theta}{\partial t} \sim-w \frac{\partial \theta}{\partial z}+\left(\frac{\theta}{T}\right) \frac{\dot{Q}}{c_{P}} .
$$

The distances between Chunghua and He-Huan Shan $(\sim 3127 \mathrm{~m})$ and between Yu-Shan $(\sim 3850 \mathrm{~m})$ and Taitung are about $150 \mathrm{~km}$. The locations of these stations are shown in Fig. 1. Using the latitude-height cross section of $\theta$ at $23^{\circ} \mathrm{N}$ across central Taiwan at 1800 UTC 17 July 2005 generated by the NCEP Global Forecast System (not 


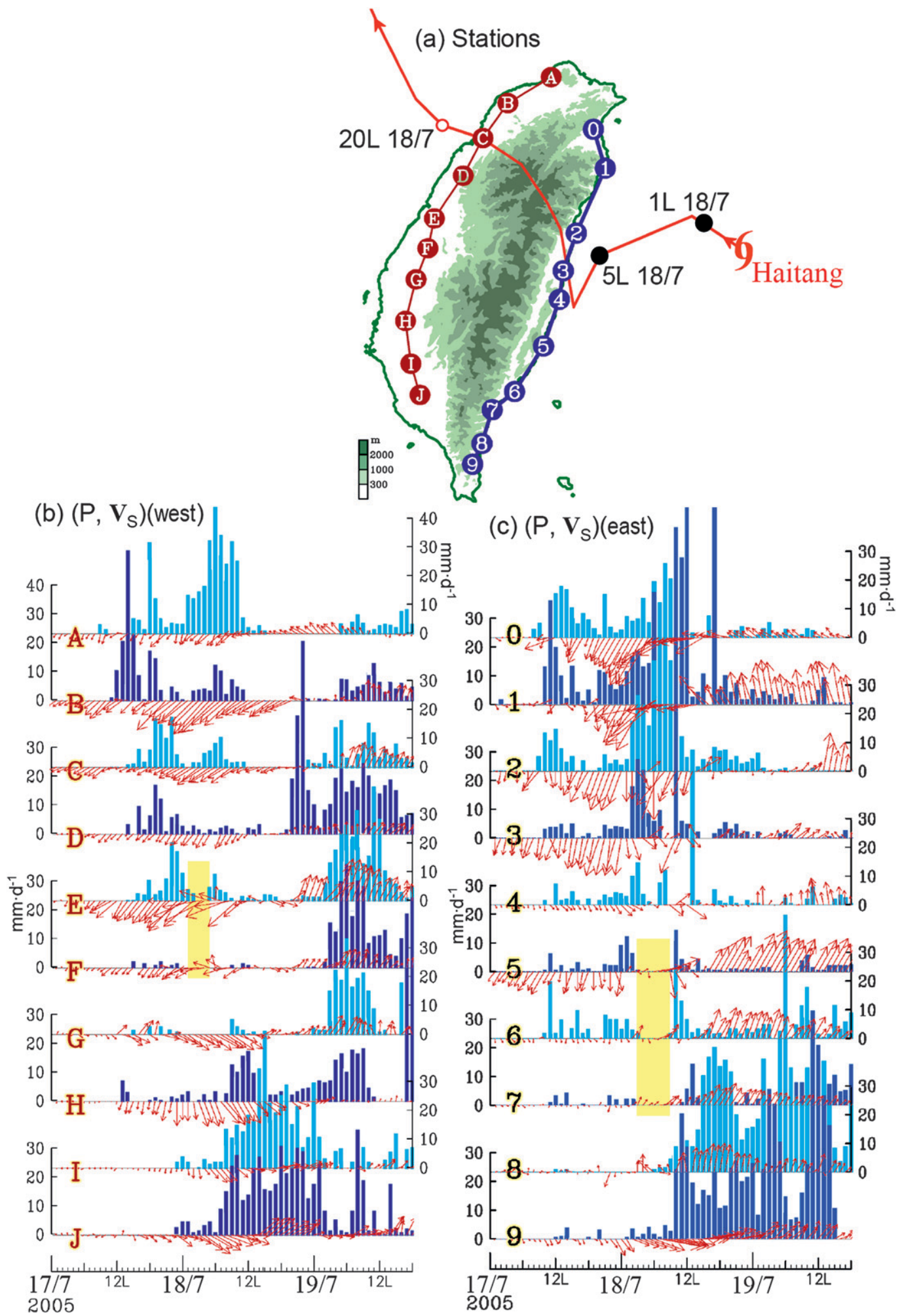

FIG. 6. Time series of rainfall (blue histogram) and wind vectors $\left(\mathbf{V}_{S}\right)$ for (a) stations marked in the (b) western plains and along (c) east coast. The trajectory of TY Haitang across Taiwan is depicted by a red line in (a), and the instantaneous locations of TY Haitang are marked by black dots with corresponding time (LST/day/month). An open circle indicates the exit time of Haitang. In (b) and (c), respectively, the warming durations are marked by yellow strips for stations $\mathrm{E}$ and $\mathrm{F}$ in the west and stations 5-7 in the east. 
shown), horizontal potential temperature gradients between the aforementioned two stations at any level in the lower troposphere between $650 \mathrm{hPa}$ and the surface are very small, except those near the surface and close to the central mountain range in Taiwan. Thus, the horizontal thermal advection is neglected in Eq. (1).

The vertical velocity that is generated by upslope or downslope flow against the terrain is

$$
w \simeq \mathbf{V}_{S} \cdot \nabla h,
$$

where $h$ represents terrain height and $\mathbf{V}_{S}$ is hourly averaged surface wind at the downwind station. Simplified terrain (i.e., stepped mountain or coarse grids) has often been used by numerical models simulating typhoon passages across Taiwan (e.g., Lin et al. 2002; Wu 2001). This approach is also adapted in this study to estimate $w$. In the numerical modeling of tropical cyclones, diabatic heating $\dot{Q}$ is generated by complex parameterization schemes involving numerous physical processes. Because typhoon rainbelts have not been well simulated by any operational model (e.g., Willoughby 1996), no attempt was made in this study to estimate $\dot{Q}$ through any parameterization approach. Often, $\dot{Q}$ is estimated diagnostically using the residual of the thermodynamic equation (e.g., Wei et al. 1983; Kasahara and Mizzi 1985; Chen and Baker 1986). Without the quality upper-level observation, it is difficult (if not impossible) to estimate $\dot{Q}$ produced over the rainbelts or nonprecipitation zone of a typhoon.

Substituting Eq. (2) into Eq. (1), an estimate of the heating rate can be expressed as

$$
\frac{\partial \theta}{\partial t} \sim-\left(\mathbf{V}_{S} \cdot \nabla h\right) \frac{\partial \theta}{\partial z}+\left(\frac{\theta}{T}\right) \frac{\dot{Q}}{c_{P}} .
$$

For convenience, Eq. (3) is expressed in a symbol form:

$$
\theta_{t} \sim \theta_{t}(\text { adiabatic })+\theta_{t}(\text { diabatic })
$$

Assuming the downslope/upslope flow is adiabatic, the change in temperature caused by this adiabatic process can be estimated using $\Delta T=\theta_{t}$ (adiabatic) $\times 1 \mathrm{~h}$. The estimated surface temperature at a downwind station $T_{W}$ is expressed as $T_{W}=T_{S}$ (downwind station) $+\Delta T$, where $T_{S}$ (downwind station) is the averaged temperature at the downwind station over the period of 17-19 July 2005. This approach focuses only on the contribution of the downslope adiabatic warming. Using these equations, the time series of $T_{W}$ (blue lines) are plotted along with observed temperatures and rainfall histograms for Chunghua in northwest Taiwan (Fig. 7a) and

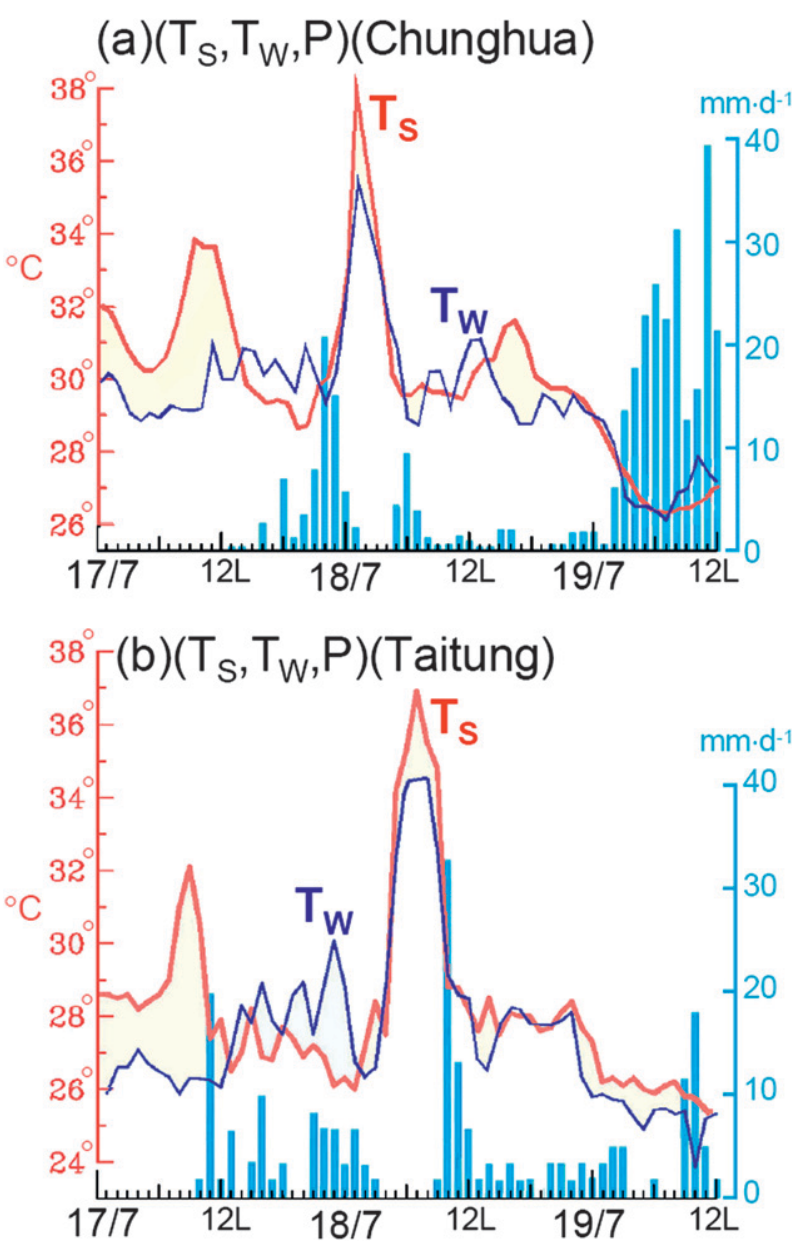

FIG. 7. Time series of $T_{S}$ and histograms of $P$ against time series of $T_{W}$ at (a) Chunghua and (b) Taitung; $T_{W}$ is calculated from the sum of $T_{S}$ (upwind station) and $\Delta T(=-w \partial \theta / \partial z$; downslope-flow adiabatic warming), by assuming the downslope flow is adiabatic and the vertical velocity $w \cong \mathbf{V}_{S} \cdot \nabla h$, where $h$ is the terrain height.

Taitung in southeast Taiwan (Fig. 7b). ${ }^{1}$ These time series generally coincide with those of $T_{S}$ at both stations, except in the morning of 17 July between 0500 and 1200 LST when surface temperature was warmed by radiative heating before rainfall (or cloudiness) started. This coincidence between $T_{S}$ (downwind station) and $T_{W}$ during the warming period is particularly significant. Because $T_{S}$ at both upwind stations exhibit only minor, gradual fluctuations within $3 \mathrm{~K}$ (not shown), the coincidence between $T_{W}$ and $T_{S}$ at the downwind stations supports the argument that adiabatic warming from downslope flow is an important process in the warming/drying events.

An effort was made to explore whether the adiabatic warming from the downslope flow caused by the passage

\footnotetext{
${ }^{1}$ The fruit farms that were severely damaged in this warming event are nearest to the city of Taitung.
} 


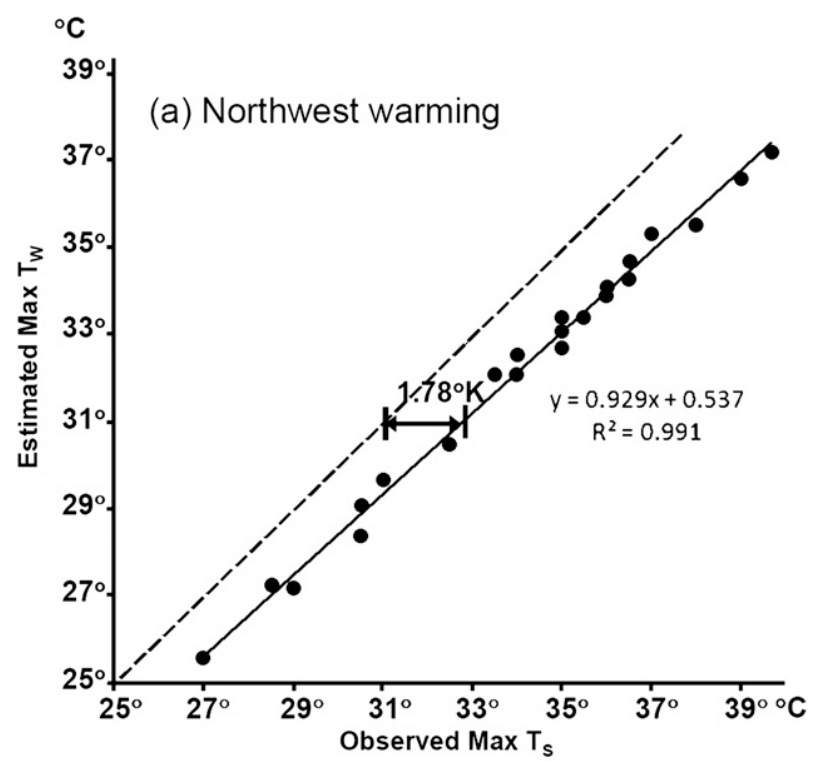

(b) Southeast warming

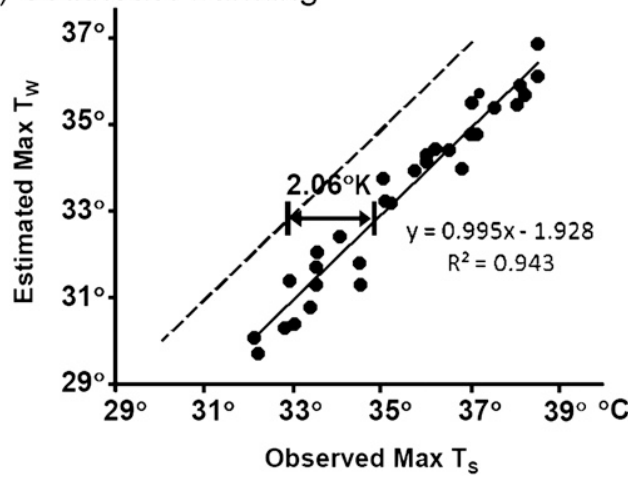

FIG. 8. Observed maximum temperature during all warmings (1961-2007) vs estimated maximum by the adiabatic warming of downslope flow $-\left(\mathbf{V}_{S} \cdot \nabla h\right)(\partial \theta / \partial z)$ : (a) northwest and (b) southeast warmings. Dashed lines indicate the 1:1 line. Squared correlation coefficient $\left(R^{2}\right)$ is given next to the fitted (thin) line.

of Haitang is applicable to other warming events. Scatter diagrams of maximum $T_{W}$ versus maximum $T_{S}$ are shown in Figs. 8a,b for the northwest and southeast groups, respectively. Least squares fit lines and squared correlation coefficients $\left(R^{2}\right)$ are added to these two scatter diagrams. Both values of $R^{2}$ are close to 1 . In comparison with the line of $T_{W}=T_{S}$, a difference of $T_{S}-T_{W} \simeq 2 \mathrm{~K}$ stands out. Regardless of the magnitude of the maximum warming temperature, this difference indicates the temperature when only considering the downslope adiabatic warming is about $2 \mathrm{~K}$ lower than the actual surface temperature.

Because subsidence outside or between typhoon rainbands may induce warming in the lower troposphere, this warming over the ocean surface enhances evaporation and increases moisture contents in the air, but over land the warmed air may stay dry. The warming-drying events at both locations occurred at times when they appeared to be outside or between typhoon rainbands. It is suggested that subsidence outside or between the rainbands may have been an additional mechanism contributing to the warming-drying in addition to the orographic subsidence. As measured for 11 typhoons with surface stations at small islands around Taiwan (Fig. 4b), the average warming from a rainbelt to the next nonprecipitation zone is about $2.2 \mathrm{~K}$. By taking this process into account, the 2-K warming from a rainbelt to the nonprecipitation zone accounts for the difference of $T_{S}$ (observation; OBS) $-T_{W}$ (estimate) shown in Fig. 8 .

\section{b. Thermal tendency caused by air mass redistribution}

A one-layer model was introduced by Mass and Dempsey (1985) for simulating surface mesoscale fields in a mountainous coastal region. The surface temperature tendency of this model is primarily generated by the air mass redistribution by the surface flow in addition to the thermal advection and diabatic heating at the surface:

$\frac{\partial T_{S}}{\partial t}=-\mathbf{V}_{S} \cdot \nabla_{h} T_{S}+\frac{R T_{S}}{c_{p}}\left(\mathbf{V}_{S} \cdot \nabla_{h} \ln p_{S}\right)+\frac{\dot{Q}}{c_{p}}$.

As shown in this equation, the $T_{S}$ tendency is produced by processes different from the downslope adiabatic warming presented in section 5a. Thus, the thermodynamic equation in this model is adopted as a validation of the diagnostic analysis with Eq. (3). Assuming the airflow is adiabatic and the surface thermal advection is negligible, the second term in the right-hand side of Eq. (5) gives us a different approach to estimate the surface temperature tendency.

Surface winds measured by stations shown in Fig. 1 at the time of maximum $T_{S}$ at Chunghua (0100 LST 17 July 2005) and close to maximum $T_{S}$ at Taitung (0500 LST 18 July 2005) were merged with the NCEP GFS and the Quick Scatterometer (QuikSCAT) ocean surface winds, respectively. The QuikSCAT satellite overpasses the vicinity of Taiwan twice daily. One overpass at 0505-0510 LST was close to the maximum southeast warming at 0600 LST. Because no QuikSCAT observations of surface winds over the ocean were available during the maximum warming at 0100 LST, the NCEP GFS surface winds were used instead. Using the Cressman (1959) scheme, the station surface winds within Taiwan were analyzed on an array of $5 \mathrm{~km} \times$ $5 \mathrm{~km}$. The QuikSCAT and NCEP GFS surface winds with the horizontal resolutions of $12 \mathrm{~km} \times 12 \mathrm{~km}$ and $0.5^{\circ}$ latitude $\times 0.5^{\circ}$ longitude, respectively, were then 
interpolated with the Bessel interpolation scheme onto the $5 \mathrm{~km} \times 5 \mathrm{~km}$ grid to merge with the analyzed surface winds within Taiwan.

Streamlines at these two times prepared with the merged surface wind of these two datasets are shown in Figs. 9a,d, superimposed with vertical motion computed with Eq. (2). Strong downward motions appear over the warming regions. Without diabatic heating $\dot{Q}$, surface temperatures $T_{S}(\mathrm{MD})$ computed with Eq. (5) in terms of a simple centered finite-difference scheme are displayed in Figs. 9b,e. The distribution pattern and magnitude of $T_{S}(\mathrm{MD})$ closely resemble those of observed surface temperature $T_{S}(\mathrm{OBS})$ in Figs. 9c,f, respectively. It appears that the major contribution to $T_{S}(\mathrm{MD})$ is derived from the airmass redistribution [the second term on the right-hand side of Eq. (5)]. To be more precise, time series of $T_{S}(\mathrm{MD})$ [integrated with Eq. (5)] and $T_{S}(\mathrm{OBS})$ averaged over the small boxes (Fig. 9) at Chunghua and Taitung are shown in Figs. 10a,b, respectively. During the maximum $T_{S}(\mathrm{OBS})$ 's at these two locations, $88 \%$ of this $T_{S}$ at Chunghua and $91 \%$ of this $T_{S}$ at Taitung can be contributed by airmass redistribution. Following Fig. 8, the scatter diagrams of $T_{S}(\mathrm{OBS})$ versus $T_{S}(\mathrm{MD})$ for all warming events after 1993 (when ARMTS observations became available) are shown in Fig. 11. The basic characteristics of these scatter diagrams are the same as those of Fig. 8. The difference between $T_{S}(\mathrm{OBS})$ and maximum $T_{S}(\mathrm{MD})$ is also about $2 \mathrm{~K}$, which matches well with the observed temperature increase from a rainbelt to the next nonprecipitation zone. In search of the warming mechanism using the thermodynamic equation of Mass and Dempsey's (1985) one-layer diagnostic model, we essentially reach the same conclusion drawn from the approach estimating the downslope adiabatic warming.

\section{Possible cause of timing difference between two warming groups}

A concern was raised in section 3 regarding the cause of the difference in the preferred arrival time and locations of typhoon centers between the northwest and southeast warming events. Most typhoons in the former group arrive during the daytime and cluster over the ocean south of Taiwan (Fig. 2b), whereas most of the latter group reach the ocean northeast of Taiwan at night (Fig. 2c). The characteristics of typhoon tracks are primarily determined by the large-scale environmental flow (Elsberry 1996). This dynamical effect of environmental flow on the motion of typhoons suggests that the day-night difference in the preferred arrival time and locations of centers of typhoons (when the warming event occurs) is likely affected by the diurnal variation of the large-scale circulation over the East Asia (EA)western North Pacific (WNP) region. Analyzing the diurnal variation in the atmospheric hydrological cycle of the Asian summer monsoon system, Chen (2006) observed that the response of the atmospheric circulation in the EA-WNP region to the westward propagation of shortwave radiative heating exhibits a clockwise rotation of the atmospheric divergent and rotational circulation. We shall explore whether this diurnal variation of regional circulation possibly influences the characteristics of typhoon tracks.

The MERRA assimilated data of 1979-2005 (Rienecker et al. 2008) and the NCEP GFS (Kanamitsu et al. 1991; Yang et al. 2006) first-day forecasts of 2006-08 were used to delineate the diurnal variation of the EA-WNP regional circulation, which could be depicted in terms of velocity potential ( $\chi$, divergent circulation) and streamfunction ( $\psi$, rotational circulation). Because the direct response of the diabatic heating is the divergent circulation, let us first focus the depiction on the clockwise rotation of the regional divergent circulation. The regular empirical orthogonal functional (EOF) analysis was applied to the diurnal component of $850-\mathrm{hPa}$ potential function, $\tilde{\chi}(850 \mathrm{hPa}$ isolated by a Fourier analysis in time. This EOF analysis generates two eigenmodes (Fig. 12) that explain $60 \%$ and $40 \%$ of the variances, respectively. Because of the difference in the heat capacities between land and water, there is a thermal contrast between the East Asian continent and the western North Pacific. This continent-ocean thermal contrast is well reflected by the first eigenvector $\mathrm{E} 1[\tilde{\chi}(850 \mathrm{hPa})]$ (Fig. 12a). In addition to the east-west differential heating, there is also a northsouth differential heating between the tropics and higher latitudes. This north-south differential heating results in a north-south dipole structure depicted by the second eigenvector E2[ $\tilde{\chi}(850 \mathrm{hPa})]$ (Fig. 12b). Attributed to the quadrature relation in their spatial structures and time series of eigencoefficient (Fig. 12) between these two eigenmodes, a clear clockwise rotation of the $\tilde{\chi}(850 \mathrm{hPa})$ field over the EA-WNP region (not shown) is well formed by them.

Because the response of the divergent circulation over the EA-WNP region to the radiative heating is a clockwise rotation, can this response also exert any effect on the regional rotational circulation and ultimately affect the typhoon tracks in this region? This possible impact may be explored with the interaction between divergent and rotational flows through the vorticity or streamfunction (inverse Laplace transform of vorticity) equation,

$$
\begin{gathered}
\tilde{\zeta}_{t}=-f \nabla \cdot \tilde{\mathbf{V}} \quad \text { or } \\
\tilde{\psi}_{t}=\nabla^{-2}(-f \nabla \cdot \tilde{\mathbf{V}}) .
\end{gathered}
$$



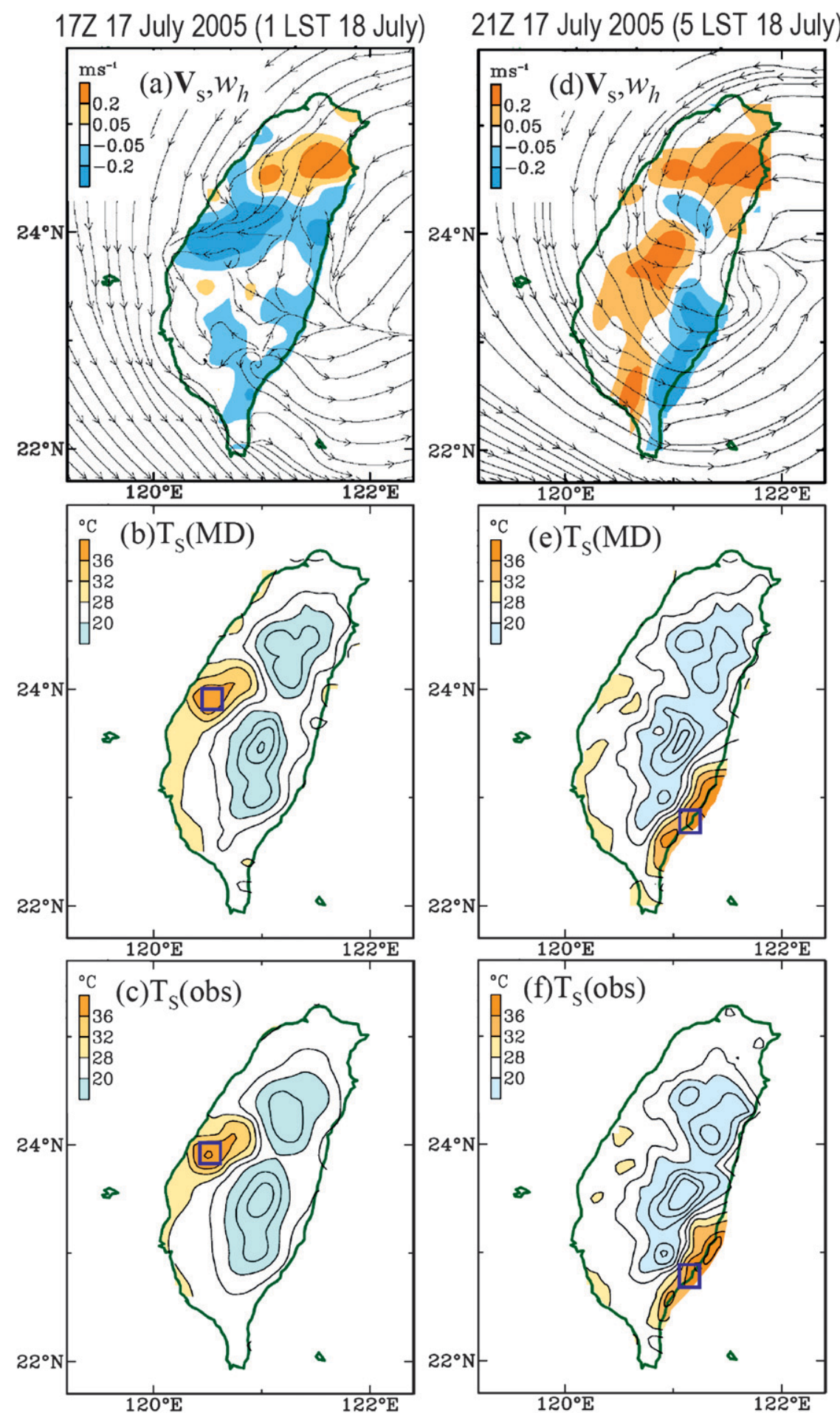

FIG. 9. (a) Merged analysis of surface winds ( $\mathbf{V}_{S}$; streamlines) using Taiwan stations, and QuikSCAT and GFS surface winds on a $5 \mathrm{~km} \times 5 \mathrm{~km}$ grid mesh (see text) superimposed with estimated vertical velocity ( $w_{h}$; shadings) following the terrain, (b) estimated surface temperature $\left(T_{S}\right)$ using the first and second terms in the rhs of Eq. (5) with a 1-h interval, and (c) actual $T_{S}$ at 0100 LST on $18 \mathrm{Jul}$ 2005. (d)-(f) As in (a)-(c), but for 0500 LST 18 Jul 2005. 


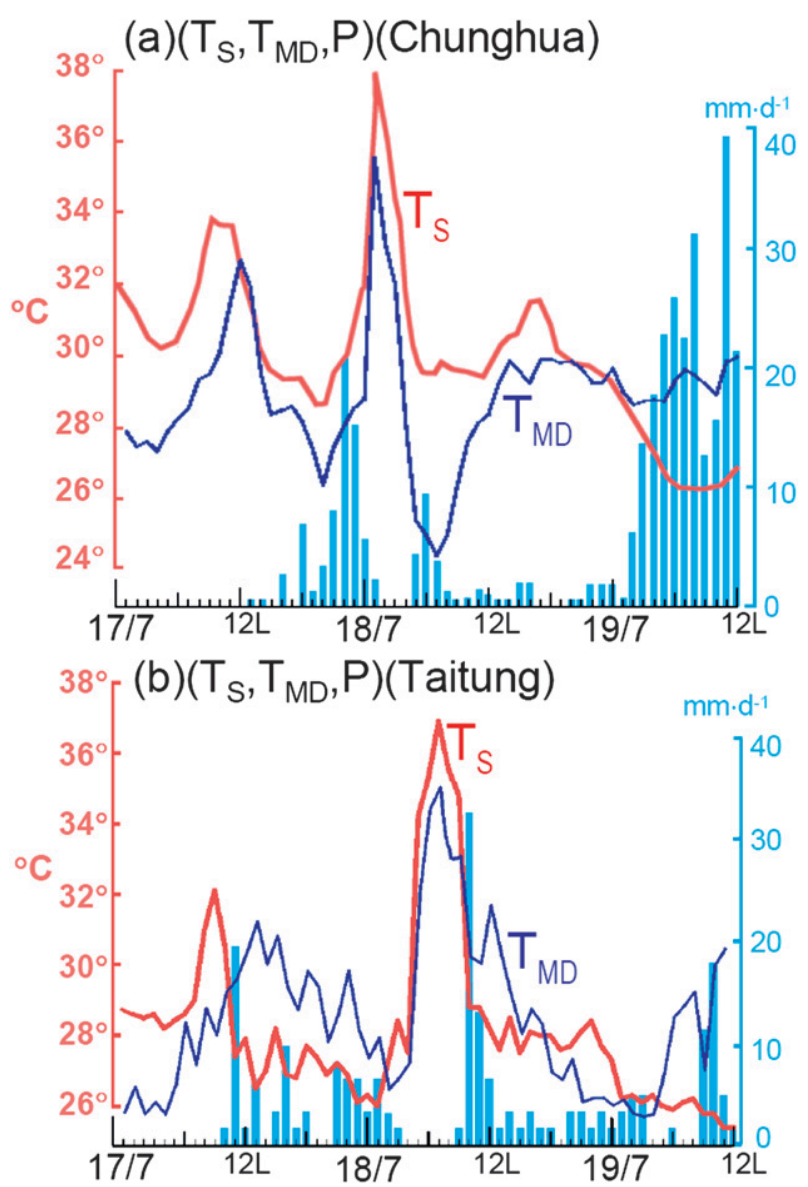

FIG. 10. Time series of actual surface temperature $\left(T_{S}\right.$; red line) at (a) Chunghua and (b) Taitung superimposed with estimated temperature derived from Figs. 10b,e, respectively, $\left[T_{S}(\mathrm{MD})\right.$; blue line] superimposed rainfall (histogram) averaged over the domain (blue box) marked in Figs. 9b,c,e,f.

The westward propagation speed of diurnal cycle mode $\left(\sim 400 \mathrm{~m} \mathrm{~s}^{-1}\right.$ at the equator) is much faster than the midlatitude westerlies $\left(\sim 50 \mathrm{~m} \mathrm{~s}^{-1}\right)$. Because of this large speed difference, the horizontal advection of vorticity is much smaller in magnitude than the vortex stretching, as far as the westward propagation of the diurnal cycle mode is concerned.

The effect of the clockwise rotation of the regional divergent circulation in response to the radiative heating on the regional rotational circulation can be revealed through the integration of Eq. (7). One can illustrate this temporal integration in terms of a simple central finite scheme,

$$
\tilde{\psi}(t+\Delta t)=\tilde{\psi}(t-\Delta t)+\nabla^{-2}(-f \nabla \cdot \tilde{\mathbf{V}})(t) 2 \Delta t
$$

where $\Delta t=3 \mathrm{~h}$ is used in this study. Let us use $t=$ $1500 \mathrm{UTC}$ (2300 LST) and $t+\Delta t=1800 \mathrm{UTC}$ (0200 LST)


FIG. 11. Observed maximum temperature during warmings of 1993-2007 vs that estimated maximum by the air mass redistribution of Eq. (5): (a) northwest and (b) southeast warmings. Dashed lines indicate the 1:1 line. Square correlation coefficient $\left(R^{2}\right)$ is given next to the fitted (thin) line.

as an example to illustrate the possible effect of diurnal cycle mode on the typhoon tracks.

The $\left(\tilde{\chi}, \tilde{\mathbf{V}}_{D}, \tilde{\zeta}_{t} ; 1500\right.$ UTC) anomalies are shown in Fig. 13a, where $\tilde{\mathbf{V}}_{D}$ and $\tilde{\zeta}_{t}$ are the diurnal component of divergent wind and vorticity tendency, respectively. The convergent center and positive vorticity tendency center (generated from vortex stretching) of the diurnal cycle mode in the EA-WNP region (indicated by the red color in Figs. 13a,b) are located northeast of Taiwan. Integrating with Eq. (8), $\tilde{\psi}(1800$ UTC) [at $0200 \mathrm{LST}$, indicated by contours in Fig. 13b] exhibits a negative (cyclonic) center between Taiwan and Japan. As inferred from the contrast between these centers, a clockwise rotation of divergent circulation followed by the regional rotational circulation may facilitate nearby typhoons to 
(a)E1[ $\tilde{\chi}(850 h P a)] ; 60 \%$
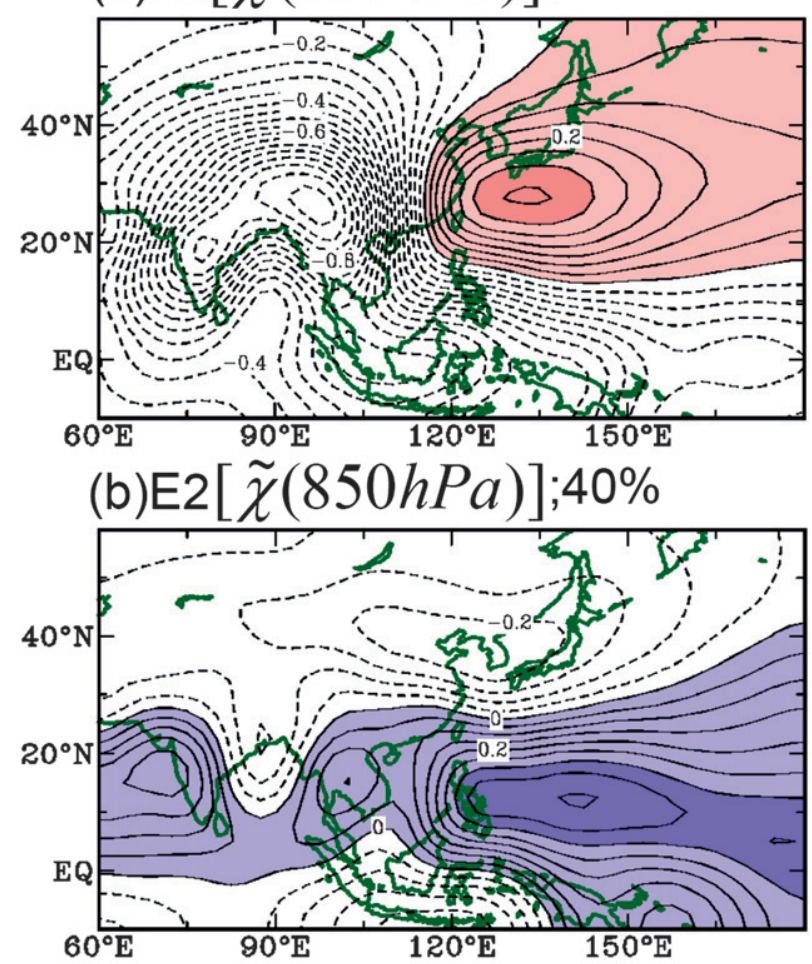

(c)Time series of $\mathrm{C} 1$ and $\mathrm{C} 2$

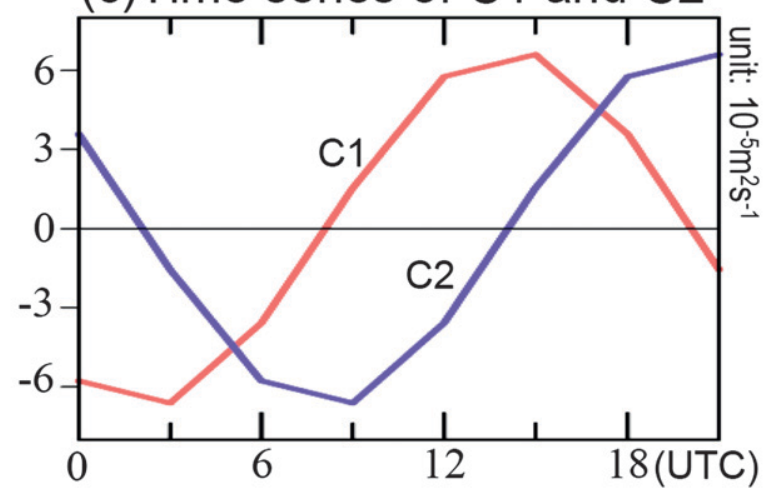

FIG. 12. EOF analysis of diurnal mode of $850-\mathrm{hPa}$ velocity potential $\tilde{\chi}(850 \mathrm{hPa})$ : (a) first eigenvector $\mathrm{E} 1[\tilde{\chi}(850 \mathrm{hPa})]$, (b) second eigenvector $\mathrm{E} 1[\tilde{\chi}(850 \mathrm{hPa})]$, and (c) time series of corresponding eigenvalues $\mathrm{C} 1$ and $\mathrm{C} 2$. Total variance of the $\tilde{\chi}(850 \mathrm{hPa})$ field explained by these two eigenmodes is $60 \%$ and $40 \%$, respectively.

move toward this region. To substantiate our inference, the composite $\psi(1800$ UTC) for all warming typhoons arriving at the region northeast of Taiwan within the time window of $\pm 3 \mathrm{~h}$ centered at 1800 UTC is shown in Fig. 13c, superimposed with composite $\zeta_{t}(1500$ UTC) and the typhoon track (solid line). The magnitude of $\tilde{\zeta}_{t}(1500$ UTC) at its center northeast of Taiwan is near $50 \%$ of the magnitude of composite $\zeta_{t}(1500$ UTC) at its center, and the negative composite $\psi(1800$ UTC) center also coincides with that of the $\tilde{\psi}(1800$ UTC) center. This comparison supports our argument that the clockwise rotation of the divergent circulation over the EA-WNP region facilitates the arrival of typhoons at night.

Following the diurnal variation of the divergent circulation in the EA-WNP region, the spatial structure of $\left(\tilde{\chi}, \tilde{\mathbf{V}}_{D}, \tilde{\zeta}_{t} ; 1500\right.$ UTC) reverses its phase at $0300 \mathrm{UTC}$ and so does $\tilde{\psi}(1800$ UTC) at 0600 UTC. The composite $\psi(0600 \mathrm{UTC})$ and $\zeta_{t}(0300 \mathrm{UTC})$ for all warming typhoons arriving in the region south of Taiwan within the time window of $\pm 3 \mathrm{~h}$ centered at 0600 UTC is shown in Fig. 13d. The comparison of the composite [ $\psi(0600$ UTC $)$, $\zeta_{t}(0300$ UTC $\left.)\right]$ center with the $[\tilde{\psi}(0600$ UTC), $\tilde{\zeta}_{t}(0300$ UTC $\left.)\right]$ center, which is opposite to those shown in Fig. 13b, suggests that the clockwise rotation of the diurnal divergent circulation blocks northward motion of nearby typhoons and tends to move them southward instead, similar to the composite track (thick dashed line). The difference charts between Figs. 2c,d, that is, $\left[\psi(1800\right.$ UTC $)-\psi(0600$ UTC $)$ and $\zeta_{t}(1500$ UTC $)-$ $\left.\zeta_{t}(0300 \mathrm{UTC})\right]$, are shown in Fig. 13e to strengthen our argument.

\section{Concluding remarks}

Despite the small geographic size of Taiwan, the interaction between typhoons and the high mountains in this island can generate sudden surface warming in the downwind areas. On average, there are 3-4 typhoon passages per year across this island, and at least one of them produces a warming event. During the 1961-2007 period, 54 warming events occurred. Several salient features of these warming events were observed:

1) Two preferred warming regions were identified: northwest and southeast Taiwan. The warming in the former region is generated by easterlies or northeasterlies of westward-propagating typhoons across the southern tip of Taiwan or the ocean south of Taiwan. The warming in the latter region is caused by the westerlies or northwesterlies of northwestwardpropagating typhoons across northern Taiwan or the ocean off the northeast coast.

2) Approximately $80 \%$ of the northwest warming events occurred during the daytime, whereas $65 \%$ of the southeast warming events happened at night. On average, the warming duration is four hours in the former region and five hours in the latter region.

3) Because radar images became available in 2001, it was observed that warming events took place exclusively within the nonprecipitation zone between typhoon rainbelts. It was measured by surface stations in 

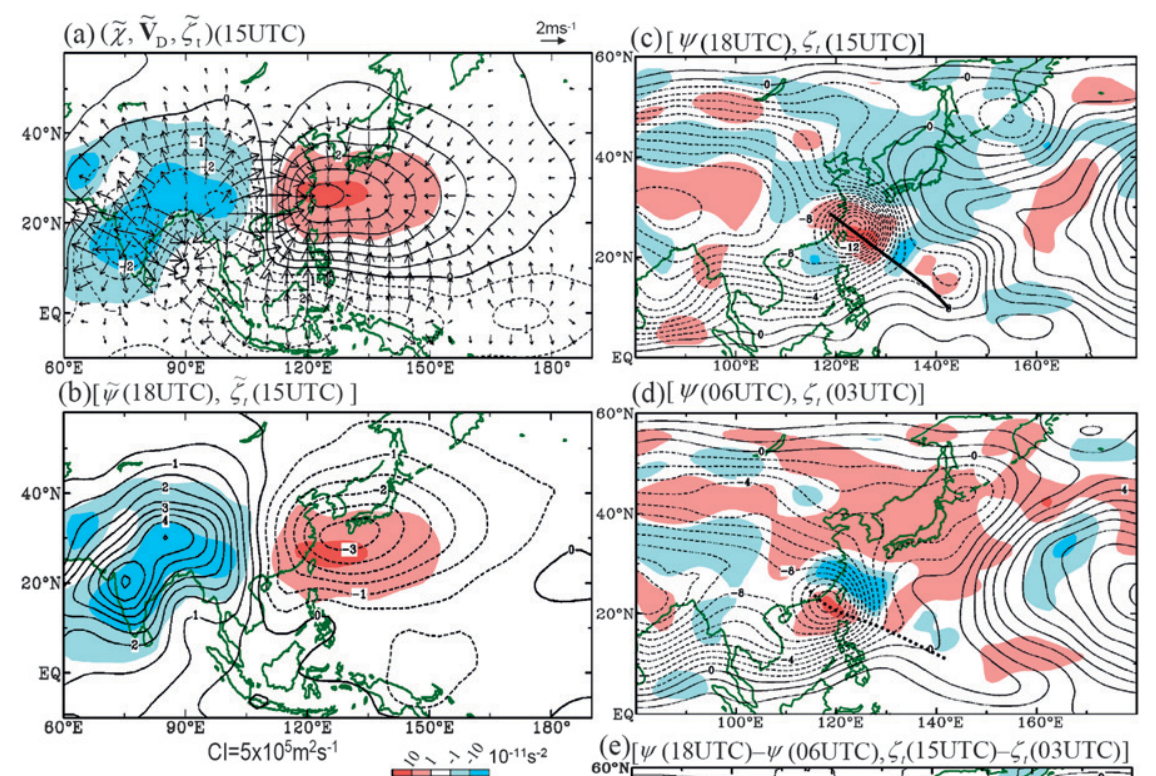

(d) $\left[\psi(06 \mathrm{UTC}), \zeta_{t}(03 \mathrm{UTC})\right]$

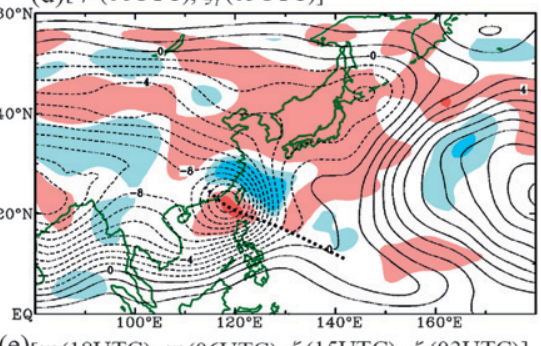

(e) $\left[\psi(18 \mathrm{UTC})-\psi(06 \mathrm{UTC}), \zeta_{t}(15 \mathrm{UTC})-\zeta_{t}(03 \mathrm{UTC})\right]$

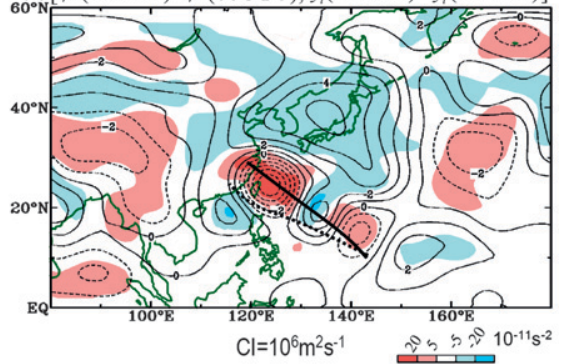

FIG. 13. Variance 850-hPa charts used to illustrate the possible impact of diurnal variation of the regional circulation on some characteristics of typhoons producing warmings: (a) $\left[\left(\tilde{\chi}, \tilde{\mathbf{V}}_{D}\right.\right.$, $\left.\left.\tilde{\zeta}_{t}\right)(1500 \mathrm{UTC})\right] ;$ (b) [ $\tilde{\psi}(1800 \mathrm{UTC})$ and $\left.\tilde{\zeta}_{t}(1500 \mathrm{UTC})\right] ;$ (c) composite [ $\left.\psi(1800 \mathrm{UTC}), \zeta_{t}(1500 \mathrm{UTC})\right]$ and track (thick solid line) for selected typhoons generating southeast warmings; (d) composite $\left[\psi(0600 \mathrm{UTC}), \zeta_{t}(0300 \mathrm{UTC})\right]$ and track (dotted line) for selected typhoons generating northwest warmings; and (e) difference between (c) and (d), i.e., [ $\psi(1800$ UTC) $-\psi(0600$ UTC) and $\left.\zeta_{t}(1500 \mathrm{UTC})-\zeta_{t}(0300 \mathrm{UTC})\right]$ with composite typhoon tracks shown in (e). Contour interval is (left) $5 \times 10^{5} \mathrm{~m}^{2} \mathrm{~s}^{-1}$ for $\tilde{\chi}\left(1500\right.$ UTC) and $\tilde{\psi}\left(1800\right.$ UTC) and (right) $10^{6} \mathrm{~m}^{2} \mathrm{~s}^{-1}$ for $\psi(1800$ UTC $), \psi(0600$ UTC $)$, and $\psi(1800$ UTC $)-\psi(0600$ UTC $)$. Scale of $\tilde{\zeta}_{t}(1500$ UTC $)$ is shown at the bottom of the left column, and that of $\zeta_{t}\left(1500\right.$ UTC), $\zeta_{t}(0300$ UTC), and $\zeta_{t}(1500 \mathrm{UTC})-\zeta_{t}(0300 \mathrm{UTC})$ is shown at the bottom of the right column.

small islands surrounding Taiwan that the averaged temperature increase from a rainbelt to the ensuing nonprecipitation zone was approximately $2 \mathrm{~K}$. On average, it took the nonprecipitation zone of typhoon four hours to move across a station. This time span matches well with the lifetime of sudden surfacewarming events.

4) During the past $47 \mathrm{yr}$, only three double warmings occurred by typhoon passages. Typhoon Haitang (7-19 July 2005) was the only one ever to produce comparable warmings $(\sim 12 \mathrm{~K})$ in both sides of Taiwan.

Based on the salient features of the sudden surface warming events observed in this study, it was hypothe- sized that such a warming is primarily caused by the adiabatic warming of the downslope flow and enhanced by an additional warming within the nonprecipitation zone of a typhoon. Two diagnostic approaches were used to substantiate this hypothesis: 1) downslope adiabatic warming and 2) thermal tendency caused by air mass redistribution. The surface sudden warmings obtained by these two different approaches $(\sim 10 \mathrm{~K})$ are very close to each other, except about $2 \mathrm{~K}$ cooler than the observed maximum warming. This discrepancy is made up for by the 2-K warming from a rainbelt to a nonprecipitation zone. The diagnostic analysis of Haitang's warmings was used as guidance to examine the other 53 warming events. The results were summarized by scatter diagrams 
of maximum $T_{S}$ (observation) versus maximum estimated $T_{W}$ [or $\left.T_{S}(\mathrm{MD})\right]$ during the warming events. The difference between these two temperatures is approximately $2 \mathrm{~K}$. This nonprecipitation zone warming between typhoon rainbelts is smaller in magnitude than the downslope adiabatic warming but is not negligible.

It was observed that most typhoons generate northwest (southeast) warmings during daytime (nighttime). During warmings, the former (latter) group of typhoons clusters over the ocean south (northeast) of Taiwan. Because the motion of typhoons is influenced primarily by the large-scale environmental flows in which these typhoons are embedded, this day-night difference in the typhoon arrival time between two regions near Taiwan suggests that the diurnal mode of the large-scale atmospheric circulation over the East Asia-western North Pacific region may affect the arrival time and locations of the typhoon. The divergent circulation in this region undergoes a clockwise rotation. It was demonstrated that the vortex stretching process caused by the clockwise rotation of this regional diurnal divergent circulation may facilitate nighttime (daytime) typhoons moving to the ocean northwest (south) of Taiwan.

Previous efforts of modeling passages of some special typhoons across Taiwan often focused on the direction and intensity change of these typhoons and the low pressure formed by the adiabatic warming. The characteristics of the sudden surface warmings observed in section 3 and the additional warming mechanism generated in the nonprecipitation zone may pose a new challenge to future numerical simulations of typhoons crossing Taiwan.

Acknowledgments. This study was primarily supported by the Cheney Research Foundation and partially by Grants NSC95-2811-M-008-009 and NSC98-2745M-008-003 (M.-C. Yen). Comments and suggestions offered by anonymous reviewers were appreciated.

\section{REFERENCES}

Bender, M. A., R. E. Tuleya, and Y. Kurihara, 1987: A numerical study of the effect of island terrain on tropical cyclones. Mon. Wea. Rev., 115, 130-155.

Chang, H. K., and W. A. Chien, 2005: Neural network with multitrend simulating transfer function for forecasting typhoon wave. Adv. Eng. Software, 37, 184-194.

Chen, S.-H., P.-H. Lee, M.-H. Yao, and Y. Shen, 2007: The agrometeorological environment and disasters occurring potential in the central region of Taiwan. Crop Environ. Bioinformatics, 4, 345-352.

Chen, T.-C., 2006: Variation of the Asian monsoon water vapor budget: Interaction with the global-scale modes. The Asian Monsoon, B. Wang, Ed., Springer, 417-457.
— , and W. E. Baker, 1986: Global diabatic heating during FGGE SPO-1 and SPO-2. Mon. Wea. Rev., 114, 2578-2589.

— M.-C. Yen, J.-C. Hsieh, and R. W. Arritt, 1999: Diurnal and seasonal variations of the rainfall measured by the automatic rainfall and meteorological telemetry system in Taiwan. Bull. Amer. Meteor. Soc., 80, 2299-2312.

—, S.-Y. Wang, and M.-C. Yen, 2007: Enhancement of afternoon thunderstorm activity by urbanization in a valley: Taipei. $J$. Appl. Meteor. Climatol., 46, 1324-1340.

Cressman, G. P., 1959: An operational objective analysis system. Mon. Wea. Rev., 87, 367-374.

Drechsel, S., and G. J. Mayr, 2008: Objective forecasting of foehn winds for a subgrid-scale Alpine valley. Wea. Forecasting, 23, 205-218.

Elsberry, R. L., 1996: Tropical cyclone motion. Global Perspectives on Tropical Cyclones, R. L. Elsberry, Ed., World Meteorological Organization Tech. Rep. WMO/TD-693, 106-197.

Kanamitsu, M., and Coauthors, 1991: Recent changes implemented into the global forecast system at NMC. Wea. Forecasting, 6, 425-435.

Kasahara, A., and A. P. Mizzi, 1985: Preliminary evolution of diabatic heating distribution from FGGE level III-b analysis data. Proc. First National Workshop on the Global Weather Experiment. Part I, Vol. 2, Washington, DC, National Academic Press, 317-329.

Li, M. H., M. J. Yang, R. Soong, and H. L. Huang, 2005: Simulating typhoon floods with gauge data and mesoscalemodeled rainfall in a mountainous watershed. J. Hydrometeor., 6, 306-323.

Liao, S. Y., 1979: Analysis of typhoon modification in relation to the foehn wind over Taiwan. Bull. Inst. Geophys., 18, 44-60.

Lin, Y.-L., J. Han, D. W. Hamilton, and C.-Y. Huang, 1999: Orographic influence on a drifting cyclone. J. Atmos. Sci., 56, 534-562.

_ D. B. Ensley, S. Chiao, and C.-Y. Huang, 2002: Orographic influences on rainfall and track deflection associated with the passage of a tropical cyclone. Mon. Wea. Rev., 130, 2929-2950.

Mass, C. F., and D. P. Dempsey, 1985: A one-level, mesoscale model for diagnosing surface winds in mountainous and coastal regions. Mon. Wea. Rev., 113, 1211-1227.

Miller, L. J., and S. M. Fredrick, cited 1998: CEDRIC (Custom Editing and Display of Reduced Information in Cartesian Space). NCAR User Manual, 130 pp. [Available online at http://www.mmm.ucar. edu/pdas/Postscript/cedric_doc.ps.]

— tererpolation). NCAR User Manual, 76 pp. [Available online at http://www.mmm.ucar.edu/pdas/Postscript/sprint_doc.ps.]

Mohr, C. G., L. J. Miller, R. L. Vaughn, and H. W. Frank, 1986: The merge of mesoscale datasets into a common Cartesian format for efficient and systematic analyses. J. Atmos. Oceanic Technol., 3, 143-161.

Powell, M. D., 1990a: Boundary layer structure and dynamics in outer hurricane rainbands. Part I: Mesoscale rainfall and kinematic structure. Mon. Wea. Rev., 118, 891-917.

_ 1990b: Boundary layer structure and dynamics in outer hurricane rainbands. Part II: Downdraft modification and mixed layer recovery. Mon. Wea. Rev., 118, 918-938.

Rienecker, M. M., and Coauthors, 2008: The GEOS-5 data assimilation system-Documentation of versions 5.0.1 and 5.1.0. NASA GSFC Tech. Rep. Series on Global Modeling and Data Assimilation, NASA/TM-2007-104606, Vol. 27, 
118 pp. [Available online at http://gmao.gsfc.nasa.gov/pubs/ docs/GEOS5_104606-Vol27.pdf.]

Wallace, J. M., and P. V. Hobbs, 2006: Atmospheric Science: An Introductory Survey. 2nd ed. Academic Press, $483 \mathrm{pp}$.

Wei, M.-Y., D. Johnson, and R. D. Townsend, 1983: Seasonal distributions of diabatic heating during the First GARP Global Experiment. Tellus, 35A, 241-255.

Willoughby, H. E., 1996: Mature structure and evolution. Global Perspective on Tropical Cyclones, World Meteorological Organization Rep. TCP-38, WMO/TD-693, 21-62.
Wu, C.-C., 2001: Numerical simulation of Typhoon Gladys (1994) and its interaction with Taiwan terrain using the GFDL hurricane model. Mon. Wea. Rev., 129, 1533-1549.

Yang, F., H. L. Pan, S. K. Krueger, S. Moorthi, and S. J. Lord, 2006: Evaluation of the NCEP Global Forecast System at the ARM SGP site. Mon. Wea. Rev., 134, 3668-3690.

Yeh, T. C., and R. L. Elsberry, 1993: Interaction of typhoons with the Taiwan orography. Part II: Continuous and discontinuous tracks across the island. Mon. Wea. Rev., 121, 3213-3233. 